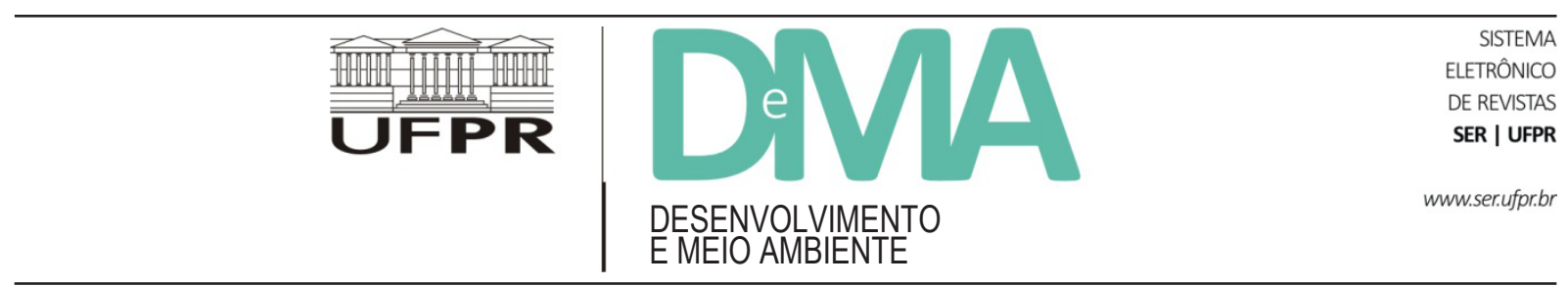

\title{
A avaliação de impactos cumulativos no planejamento ambiental de hidrelétricas na bacia do rio Teles Pires (região amazônica)
}

\section{The Evaluation of Cumulative Impacts in the Environmental Planning of Hydroelectric Plants in the Teles Pires River Basin in the Amazon Region}

\author{
Amarilis Lucia Casteli Figueiredo GALLARDO ${ }^{1,2^{*}}$, João Carlos da SILVA², Guilherme Leite GAUDERETO², \\ Davi Wilkson Furtado SOZINHO ${ }^{3}$ \\ ${ }^{1}$ Departamento de Engenharia Hidráulica e Ambiental, Escola Politécnica, Universidade de São Paulo (USP), São Paulo, SP, Brasil. \\ ${ }^{2}$ Programa de Mestrado em Gestão Ambiental e Sustentabilidade e Programa de Mestrado em Cidades Inteligentes e Sustentáveis, Universidade \\ Nove de Julho (Uninove), São Paulo, SP, Brasil. \\ ${ }^{3}$ Universidade Federal do ABC (UFABC), Santo André, SP, Brasil. \\ *E-mail de contato: amarilislcfgallardo@gmail.com
}

Artigo recebido em 9 de julho de 2017, versão final aceita em 14 de novembro de 2017.

RESUMO: As bacias do rio Amazonas concentram grande parte das hidrelétricas projetadas para atender as demandas de energia elétrica nacional. O debate sobre os significativos impactos socioambientais do avanço da fronteira hidrelétrica para a região amazônica tem sido intenso. Dada a vulnerabilidade socioambiental da região amazônica frente às hidrelétricas, torna-se relevante discutir os impactos cumulativos associados. O planejamento do setor hidrelétrico utiliza dois instrumentos de avaliação de impacto: Estudo de Impacto Ambiental (EIA), para análise da viabilidade ambiental das hidrelétricas, e a Avaliação Ambiental Integrada (AAI), para análise dos impactos do conjunto de hidrelétricas em uma bacia hidrográfica. O recorte territorial da pesquisa concentra-se na bacia do rio Teles Pires, uma das principais da região amazônica, em que está projetada uma série de aproveitamentos hidrelétricos. O objetivo geral foi analisar a avaliação de impactos cumulativos desde a escala de bacia até a de hidrelétricas por meio dos instrumentos de avaliação de impacto. Na análise dos dados, utilizou-se instrumento de pesquisa que sintetiza orientações para avaliação de impactos cumulativos em bacias hidrográficas e critérios para associação desses impactos em bacia e em empreendimentos. Os principais resultados revelam que: a) algumas das boas práticas internacionais de avaliação de impactos cumulativos na escala de bacia estão presentes no planejamento ambiental de hidrelétricas; b) a análise de impactos cumulativos na bacia considera apenas os efeitos de empreendimentos do setor hidrelétrico; c) os impactos cumulativos identificados em nível de bacia hidrográfica - na AAI - foram parcialmente observados nas hidrelétricas - nos EIAs. Não obstante o mérito do setor para integrar a avaliação de impactos cumulativos nas bacias na tomada de decisão, para garantir a efetividade do instrumento recomenda-se: ampliar o escopo dessa análise para 
outras ações além das hidrelétricas e adotar procedimentos para realização do EIA que permitam a adequada avaliação dos impactos cumulativos em nível de empreendimentos hidrelétricos.

Palavras-chave: impactos cumulativos; impactos ambientais; avaliação de impacto ambiental; planejamento de hidrelétricas; hidroeletricidade.

ABSTRACT: The Amazon River basins concentrate a large part of the hydroelectric plants planned to meet the national electricity demands. The debate about the significant socio-environmental impacts associated with the advancement of hydroelectric frontiers in the Amazon region has been intense. Due to the socio-environmental vulnerability of the Amazon region to the hydroelectric dams, it is relevant to discuss the associated cumulative impacts. The planning of the hydropower sector uses two impact assessment tools: the Environmental Impact Study (EIS), for analyzing the environmental feasibility of hydroelectric dams, and the Integrated Environmental Assessment (IEA), for analyzing impacts from a set of hydroelectric into watershed. The research focuses on "Teles Pires" river basin where a series of hydropower projects has been planned. The objective was to analyze the assessment of cumulative impacts from the watershed to the hydroelectric through the impact assessment instruments. A research instrument has been used to synthesize guidelines for the evaluation of cumulative impacts in watershed and criteria was used to associate impacts in the watershed and in the individual hydropower projects. The main results reveal that: a) some of the good international practices for assessing cumulative impacts in watersheds are present in the environmental planning of hydroelectric dams; b) the analysis of cumulative impacts in the basin considers only the effects of hydroelectric projects; c) the cumulative impacts identified at the river basin level - in the IEA - were partially observed in the hydroelectric dams - in the EISs. The sector has the merit of integrating cumulative impacts assessment principles in taking decision in watersheds. However to guarantee the effectiveness of the instrument it is recommended to extend the scope of this analysis to other actions besides the hydroelectric ones. More value can be achieved by adopting procedures to carry out the EIS embedded in good practices for considering cumulative impacts at the level of hydroelectric projects.

Keywords: cumulative impacts; environmental impacts; environmental impact assessment; hydropower planning; hydroelectricity.

\section{Introdução}

O Brasil é reconhecidamente um país abundante em recursos naturais, particularmente água. Regiões do território nacional com caudalosos rios encontram-se cobertas por biomas de elevada diversidade biológica e remanescentes de populações tradicionais (ribeirinhos e indígenas), como a região amazônica. Dentre os usos múltiplos do grande potencial hídrico nacional, destacam-se aqueles de fins energéticos. Segundo dados recentes da agência responsável pela regulação de energia elétrica no país (ANEEL, 2017), o potencial hidráulico representa atualmente $61,341 \%$ da matriz de energia elétrica, produzindo $98.059,082 \mathrm{MW}$ de energia a partir de 1.254 usinas hidrelétricas em operação no país.
Não obstante a representatividade da energia hidrelétrica na matriz de energia elétrica nacional, ainda resta um extraordinário potencial para exploração. Bermann (2007), há dez anos, apontava que o Brasil possuía uma capacidade instalada de usinas hidrelétricas em operação que não representava mais que $28,4 \%$ do potencial hidrelétrico total brasileiro, sendo que "praticamente a metade desse potencial $(50,2 \%)$ encontra-se localizada na região amazônica, principalmente nos rios Tocantins, Araguaia, Xingu e Tapajós" (Bermann, 2007, p. 140).

Apesar da diminuição da oferta primária de energia elétrica produzida por hidrelétricas nos últimos anos (EPE, 2016), o planejamento do setor elétrico nacional direciona-se para ampliar o aproveitamento desse potencial hídrico. Fearnside 
(2015) destaca que o país tenciona construir 43 grandes hidrelétricas, 10 das quais previstas para serem concluídas antes de 2022 na bacia do rio Tapajós, na região amazônica.

Ao mesmo tempo, é histórico o legado negativo ao ambiente tributado às hidrelétricas na bacia amazônica, percebido desde o ínicio dos anos 1990 por Junk \& Mello (1990). Moretto et al. (2012) destacam que as vulnerabilidades socioambientais amazônicas contrastam com a ampla disponibilidade do potencial hidrelétrico. Segundo estes autores, os mesmos elementos do acirrado debate da viabilidade ambiental da UHE Belo Monte podem ser acentuados nos processos de avaliação de impacto ambiental das novas hidrelétricas projetadas para a região. Para Fearnside (2016), os impactos socioambientais associados a hidrelétricas na Amazônia são muito mais severos e amplos que os comumente apresentados pelos proponentes, estendendo-se por toda a bacia hidrográfica do barramento.

Dentre os impactos socioambientais, destacam-se os impactos cumulativos, que, de acordo com Wärnbäck \& Hilding-Rydevik (2009), são aqueles resultantes de uma ação que se somam aos de outras ações do passado, presente e até do futuro. Se os impactos são recorrentes temporalmente ou tornam-se mais frequentes em uma determinada área, a capacidade de assimilação dos sistemas ambientais modifica-se, caracterizando-os como significativos (Cooper, 2004).

No caso de bacias hidrográficas, pode-se considerar que impactos cumulativos decorrem de impactos, pouco ou muito significativos, de múltiplos aproveitamentos hidrelétricos em uma bacia, cuja somatória pode configurar um impacto significativo. Para o enfrentamento da complexidade de problemas ambientais resultantes da implantação de projetos de hidrelétricas, destacada por Bermann (2007), revela-se a necessidade de utilizar ferra- mentas para analisar os impactos cumulativos em bacias hidrográficas.

De acordo com o Ministério de Minas e Energia (2007), o setor elétrico, por ser um dos principais usuários de recursos hídricos no país, tem por responsabilidade planejar a utilização desse recurso de modo racional, não somente dos pontos de vista técnico e econômico, mas também socioambiental, considerando-se o cenário de utilização múltipla da água na bacia hidrográfica.

Nesse escopo, alguns órgãos estaduais de licenciamento ambiental, como os do Paraná, do Rio Grande do Sul e de Goiás, foram pioneiros ao incluir a análise dos impactos ambientais não limitada ao empreendimento, mas englobando a bacia hidrográfica (Tucci \& Mendes, 2006). A partir desse conhecimento inicial fornecido por esses órgãos ambientais e do setor elétrico, o Ministério do Meio Ambiente, por meio do Instituto Brasileiro do Meio Ambiente e dos Recursos Naturais Renováveis (IBAMA), responsável pelo licenciamento ambiental de empreendimentos hidrelétricos em nível federal desde 2003, passou a detalhar um novo instrumento de planejamento que contemplasse na bacia hidrográfica os impactos de múltiplos aproveitamentos hidrelétricos (Tucci \& Mendes, 2006).

Desde então, o planejamento ambiental do setor hidrelétrico brasileiro vem considerando o uso de dois instrumentos de avaliação de impacto: a Avaliação Ambiental Integrada (AAI), com a finalidade de avaliar os efeitos cumulativos e sinérgicos provocados pelo conjunto de múltiplos aproveitamentos hidrelétricos inseridos na bacia; $\mathrm{e}$ o Estudo de Impacto Ambiental (EIA), com propósito complementar à AAI, consolidando os estudos socioambientais da alternativa de usina hidrelétrica selecionada (Ministério de Minas e Energia, 2007).

Com isso, o Brasil entrou em consonância com outros países que vêm utilizando a Avaliação 
de Impactos Cumulativos (AIC) como uma ferramenta para avaliação de impactos. Para Cardinale \& Greig (2013), a AIC permite analisar os impactos potenciais de um dado empreendimento, somados a potenciais efeitos de outras atividades humanas, para propor medidas para evitar, reduzir e/ou mitigar os impactos cumulativos.

De acordo com Westin et al. (2014), frente às preocupações ambientais e sociais decorrentes das implantações de projetos hidrelétricos no país, 14 AAIs foram realizadas para bacias hidrográficas brasileiras, principalmente na região da bacia amazônica, na qual se localiza boa parte das novas usinas hidrelétricas projetadas.

Na região amazônica, na bacia do rio Tapajós (afluente do rio Amazonas), o rio Teles Pires é um dos dois tributários principais (o outro é o rio Juruena), abrangendo parte dos estados do Mato Grosso e Pará, possuindo aproximadamente $141.483 \mathrm{~km}^{2}$ de área de drenagem e $3.647 \mathrm{~km}$ de extensão (Empresa de Pesquisa Energética, 2009). A partir do inventário realizado na bacia pela Eletrobras, que identificou um potencial de 3.697 MW de energia, foi estabelecido um conjunto de aproveitamentos hidrelétricos compreendendo seis usinas hidrelétricas (UHEs Magessi, Sinop, Colíder, Teles Pires, Foz do Apiacás e São Manoel) e sete pequenas centrais hidrelétricas (PCHs Ilha Pequena, Nhandu, Rochedo, Cabeça do Boi, Salto Apiacás, da Fazenda e Salto Paraíso). A Empresa Brasileira de Pesquisa Energética (EPE), responsável pela realização de estudos ambientais para aproveitamento de energia, realizou, em 2009, a AAI da bacia do rio Teles Pires (Empresa de Pesquisa Energética, 2009). Dos seis aproveitamentos hidrelétricos, à exceção da UHE Magessi, os outros cinco encontravam-se em processo de licenciamento ambiental na virada da década passada (Empresa de Pesquisa Energética, 2009).

Selecionaram-se como objeto de análise os estudos ambientais realizados na bacia do rio Teles Pires com vistas ao planejamento hidrelétrico, estabelecendo-se como questão de pesquisa: Como os impactos cumulativos de aproveitamentos hidrelétricos inseridos em bacia hidrográfica na região amazônica estão sendo analisados nos instrumentos de planejamento ambiental por meio da Avaliação Ambiental Integrada e do Estudo de Impacto Ambiental? Os pressupostos da pesquisa acerca do planejamento ambiental de hidrelétricas em bacias hidrográficas brasileiras referem-se a: evidências de boas práticas de avaliação de impactos cumulativos são encontradas na AAI; e impactos cumulativos em nível de empreendimentos hidrelétricos não são adequadamente considerados, mesmo em casos em que há avaliação de impactos cumulativos em bacias hidrográficas.

A partir desses pressupostos, estabelece-se como objetivo geral da pesquisa analisar a avaliação de impactos cumulativos da escala de bacia do rio Teles Pires à escala de empreendimentos hidrelétricos, por meio dos instrumentos de avaliação de impacto ambiental aplicados ao planejamento ambiental. Os objetivos específicos referem-se a: analisar os procedimentos de AIC empregados na AAI da bacia do rio Teles Pires; e analisar a associação dos impactos cumulativos da AAI aos impactos apresentados em cinco EIAs realizados nesta bacia.

A estrutura do artigo contempla, além desta introdução, um item que aborda elementos de revisão bibliográfica para a definição do método e análise dos dados, outro de métodos, seguido dos resultados e discussão e finalmente pelas conclusões. 


\section{Planejamento ambiental de hidrelétricas: da tradicional Avaliação de Impacto Ambiental à Avaliação de Impactos Cumulativos}

No contexto da pesquisa, algumas considerações prévias sobre avaliação de impacto e avaliação de impactos cumulativos merecem destaque: a) a prática usual de avaliação de impacto no Brasil dá-se em nível de projeto, em que não é comum a consideração dos impactos cumulativos (Sánchez, 2013); b) a necessidade da avaliação das consequências socioambientais de hidrelétricas na região amazônica que envolva interferências de reservatórios em terras indígenas e sobre a biodiversidade, para além do otimismo daqueles que defendem essa opção de geração de energia (Bermann, 2007); c) a avaliação de impactos cumulativos que cumpra papel de fornecer ao tomador de decisão informações acerca dos efeitos sobre as componentes ambientais para o planejamento ambiental (Canter \& Kamath, 1995); d) a necessidade de se realizar a AAI e EIA no Brasil para aproveitamentos hidrelétricos (Tucci \& Mendes, 2006); e) a oportunidade que o tiering ou encadeamento entre instrumentos de avaliação de impacto em etapas sucessivas do planejamento pode oferecer na mitigação de impactos (Turco \& Gallardo, no prelo).

A AIA é um instrumento de planejamento ambiental que visa avaliar os impactos ambientais associados às atividades humanas (Sánchez, 2013). É considerada um dos instrumentos de planejamento ambiental mais aplicados no mundo (Morgan, 2012). Segundo Gallardo \& Sánchez (2004), na prática de AIA brasileira, o EIA é apresentado pelo proponente considerando os impactos ambientais do projeto e mecanismos para sua atenuação. Para Landim \&e Sánchez (2012), é o documento técnico que orienta o processo de AIA, compreendendo o diagnóstico ambiental, a avaliação de impacto, a previsão de medidas mitigadoras e o acompanhamento ambiental, devendo demonstrar a viabilidade ambiental do projeto proposto.

De acordo com Almeida et al. (2012), a qualidade dos estudos de impacto ambiental é relevante para garantir um bom desempenho da AIA. Gallardo \& Bond (2011) consideram que o EIA deve apresentar uma análise integrada dos impactos ambientais com vistas à promoção do desenvolvimento sustentável. Dentre algumas críticas à qualidade do EIA encontra-se a limitada avaliação de impactos regionais (Sánchez, 2013). Por outro lado, segundo Landim \& Sánchez (2012) e Borioni et al. (2017), em comparação aos primeiros EIAs preparados no país, o escopo desses estudos tem-se aprofundado ao longo do tempo.

Com relação aos impactos cumulativos, de acordo com Dibo (2013), há dois mecanismos de manifestação dessa categoria de impactos: o processo aditivo e o sinérgico, em que o primeiro se refere a impactos da mesma natureza que se somam e o segundo decorre de ações distintas, resultando em um impacto de natureza diferente e de consequência mais ampla.

A AIC foi definida por Spaling (1994) como um processo de avaliação e análise sistemáticas das mudanças cumulativas ambientais. De acordo com Gunn e Noble (2011), a AIC ainda é um dos maiores desafios da prática de avaliação de impacto. Bidstrup et al. (2016, p. 157) ainda agregam que “[...] avaliação de impactos cumulativos é um elemento essencial na avaliação de impacto, que vem sendo mal executado no mundo inteiro". Segundo Atkinson \& Canter (2011), a condução da AIC engloba a análise de um grande conjunto de dados que envolve múltiplas ações, recursos ambientais, seleção de indicadores e fatores que deflagram impactos ambientais associados à distribuição espacial e temporal das ações. 
Na Europa, o uso da AIC é obrigatório, segundo Cooper \& Sheate (2004), assim como no Canadá (Gunn \& Noble, 2011). No Brasil, embora prevista a necessidade de avaliar os impactos cumulativos na tomada de decisão desde a Resolução Conama 001/86 (Sánchez, 2013), reconhecem-se apenas algumas iniciativas. Gallardo \& Bond (2011) destacam que a legislação específica do setor de etanol paulista recomenda que se realize AIC das usinas, embora Dibo (2013) tenha constatado resultados tímidos em análise sobre EIAs do setor. Recentemente, em 2017, o Ibama aprovou o plano de trabalho para realização de análise de impactos cumulativos dentro do licenciamento ambiental das etapas 1 e 2 do Pré-Sal da Petrobras ${ }^{1}$.

Nas construções de grandes usinas hidrelétricas, ocorrem impactos ambientais positivos e negativos e somam-se os impactos cumulativos, que no Brasil, segundo Sánchez (2013), ainda são pouco considerados no planejamento ambiental. Segundo Junk \& Mello (1990), os principais impactos ecológicos das represas hidrelétricas na bacia amazônica brasileira estavam associados: à translocação da população, perda de solos, perda de espécies de plantas e animais, perdas de monumentos naturais e históricos, perda de recursos madeireiros, modificação da geometria hidráulica do rio e na hidrologia, modificações da carga sedimentar, mudanças florísticas e faunísticas a montante e a jusante da represa, impactos para a pesca e para a agricultura, crescimento maciço de macrófitas aquáticas, deterioração da qualidade da água, problemas sanitários, emissões de $\mathrm{CO}_{2}$, dentre outros.

Diferente de outros setores de tomada de decisão no Brasil, de acordo com Westin et al. (2014), desde 2007, o inventário do potencial hidrelétrico brasileiro tem sido submetido à AAI levando-se em consideração a análise dos impactos cumulativos e sinérgicos de todos os projetos de hidrelétrica numa bacia hidrográfica. A AAI, para Tucci \& Mendes (2006), é definida como a avaliação da situação ambiental da bacia com os empreendimentos hidrelétricos implantados e os potenciais barramentos, considerando: (i) seus efeitos cumulativos sobre os recursos naturais e as populações humanas; e (ii) os usos atuais e potenciais dos recursos hídricos, considerando-se a necessidade de compatibilizar a geração de energia com a conservação da biodiversidade, a sociodiversidade e a tendência de desenvolvimento socioeconômico da bacia, à luz da legislação.

Um aspecto relevante da aplicação da AIC é o nível de decisão a que se aplica. Gallardo et al. (2016) reforçam que a AIA de projetos não se caracteriza por avaliar os impactos cumulativos de grupamentos de empreendimentos de mesmas ou de naturezas distintas, não permitindo que as implicações regionais e cumulativas de projetos individuais somados sejam devidamente consideradas. Para Cooper \& Sheate (2004), a consideração dos impactos cumulativos em projetos individuais pode reduzir a contribuição incremental desses impactos na região afetada pelo empreendimento. Ainda segundo esses autores, o uso da AIC no planejamento estratégico, no caso de bacias hidrográficas, tende a evitar a geração de impactos cumulativos, antecipando-os no processo de planejamento. Segundo Gunn \& Noble (2011), muitos autores consideram limitado o uso da AIC para projetos e para os quais os efeitos cumulativos são melhor avaliados em contexto regional ou estratégico. De acordo com Joseph et al. (2017), há uma crítica de longa data sobre a baixa capacidade da avaliação de impacto ambiental de projetos individuais em integrar os efeitos cumulativos, por isso a argumentação re-

\footnotetext{
$1<$ http://www.comunicabaciadesantos.com.br/programa-ambiental/projeto-de-avaliacao-de-impactos-cumulativos-paic.html $>$.
} 
corrente que esses efeitos são melhor avaliados em escala regional. Nesse contexto da avaliação dos impactos cumulativos da escala regional - de bacia - para a escala de hidrelétricas, surge a oportunidade para superar as barreiras da não consideração do tiering ou encadeamento na prática de avaliação de impacto no Brasil, como destacado por Fonseca et al. (2017), e de auferir os benefícios proporcionados pelo encadeamento que, de acordo com Sánchez \& Silva-Sánchez (2008), permite maior eficácia na tomada de decisão.

Noble et al. (2011) destacam que a prática de AIC deve abranger, além da escala de projetos individuais, também as considerações de escala regional, remetendo às fontes das mudanças dos impactos cumulativos. Para esses autores, a escala regional remete a bacias hidrográficas, mas as oportunidades de aplicação do instrumento encontram-se tanto na escala de bacia quanto na escala de projetos. Ainda segundo esses mesmos autores, os desafios para avançar na AIC em bacias hidrográficas, independente da escala de análise, referem-se a: nível de compreensão e concordância acerca da natureza e definição dos impactos ambientais cumulativos; recorte de análise; necessidade de criação de um banco de dados de monitoramento da qualidade de água para avaliar e gerenciar os impactos cumulativos nas bacias hidrográficas; necessidade de dados e parâmetros consistentes coletados; a questão dos limiares dos efeitos cumulativos que podem variar entre ser aceitáveis para o nível de projetos e inaceitáveis para o nível de bacia; a capacidade da regulamentação vigente em capturar os efeitos cumulativos.

Segundo Seitz et al. (2011, p. 172), os “projetos inseridos em bacias hidrográficas interagem de uma maneira aditiva e sinérgica ao longo do tempo e do espaço", ameaçando a sustentabilidade dos recursos hídricos em todo o mundo. Segundo esses autores, a prática de AIC tem falhado, devendo ser propostas melhorias para o uso desse instrumento em bacias hidrográficas. Por sua vez, Canter et al. (2013) realizaram uma ampla revisão sobre orientações e métodos para o planejamento de recursos hídricos, sintetizando um roteiro para AIC nesse contexto.

A prática de AIC direciona-se a analisar as pressões que são exercidas sobre as componentes ambientais valorizadas (Bidstrup et al., 2016), as quais, segundo Olagunju \& Gunn (2013), são imprescindíveis para garantir bons resultados da AIC.

Na prática nacional, segundo Tucci \& Mendes (2006), assim como o EIA, a AAI realiza a avaliação nas três dimensões ambientais - antrópica, física e biótica -, mas considera o meio biofísico em ambientes terrestre e aquático. Os meios antrópico e terrestre extrapolam os limites da bacia hidrográfica, mas o aquático está inserido nesses limites. A AAI dá a ênfase à bacia hidrográfica, mas considera que o alcance dos impactos extrapola a área da barragem para montante e jusante da mesma. A análise da AAI também pode abranger os meios antrópico e físico, desde que sejam observados aspectos sensíveis - os componentes ambientais valorizados, conforme o jargão internacional de AIC.

\section{Método}

O objeto da pesquisa refere-se aos estudos ambientais concluídos para o planejamento ambiental das hidrelétricas na bacia do rio Teles Pires (Figura 1), a saber: AAI da bacia do rio Teles Pires (Empresa de Pesquisa Energética, 2009); e os cinco EIAs: UHE Colider (JGP Consultoria e Participações Ltda., 2009); UHE Teles Pires (Empresa de Pesquisa Energética, 2010a); UHE Sinop (Themag, 2010); UHE Foz do Apiacás (Empresa de Pesquisa Energética, 2010b); UHE São Manoel (Empresa de Pesquisa Energética, 2011). 


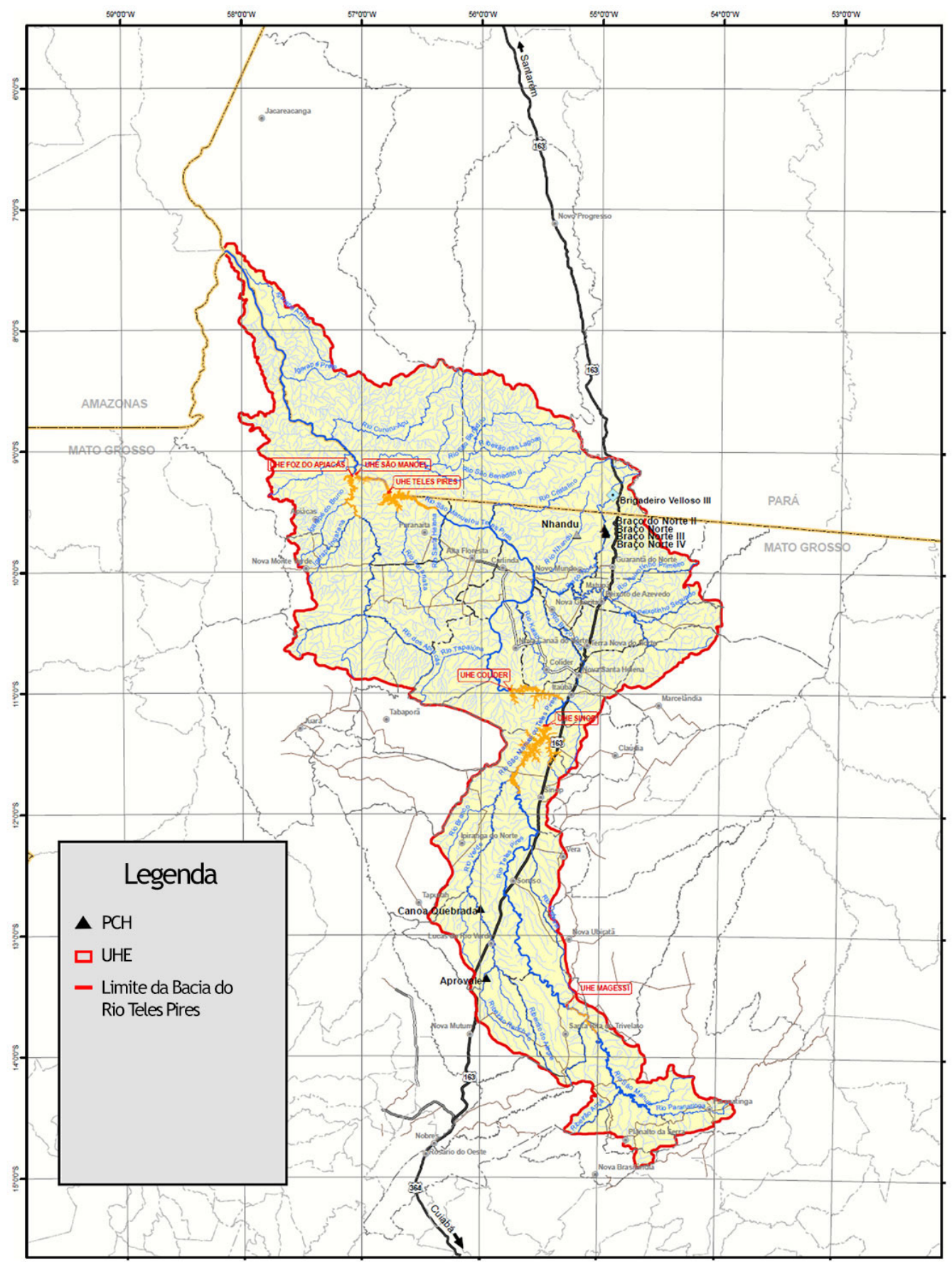

FIGURA 1 - Mapa de localização da Bacia do rio Teles Pires. FONTE: Modificado de Empresa de Pesquisa Energética (2009). 
Esses estudos constituem as fontes documentais para análise, complementadas pelos registros em arquivos disponíveis em fontes oficiais (sítios da Empresa de Pesquisa Energética e Aneel, dentre outros $^{2}$ ) subsidiados pelo referencial bibliográfico para definição do instrumento de pesquisa e análise de dados.

\subsection{Análise da Avaliação de Impactos Cumulativos na Avaliação Ambiental Integrada}

Como não há prática e tampouco referencial conceitual-teórico estabelecidos no país com a AIC, optou-se por utilizar para análise documental da AAI da bacia hidrográfica do rio Teles Pires (Em- presa de Pesquisa Energética, 2009) um instrumento publicado e testado previamente. Nesse contexto, destaca-se o trabalho produzido por Canter et al. (2013), que sintetizaram, por meio de uma ampla revisão, orientações e métodos para levantamento e análise de impactos cumulativos.

Os métodos apresentados por Canter et al. (2013) consolidam trabalhos prévios realizados pelo Conselho Canadense de Qualidade Ambiental (1999) e por Canter \& Ross (2010) apud Canter et al. (2013). Desse modo, esses autores consolidaram listas de verificação para avaliação de impactos cumulativos no contexto de planejamento de recursos hídricos, conforme apresentado nas Tabelas 1,2 e 3. Considera-se que essas tabelas sintetizam boas práticas de AIC em bacias hidrográficas.

TABELA 1 - Lista de Verificação para Análise da AAI da bacia do rio Teles Pires frente aos 11 passos do processo

\begin{tabular}{|c|c|}
\hline $\begin{array}{c}\text { Componentes da Avaliação de } \\
\text { Impacto }\end{array}$ & Etapas para consideração dos impactos cumulativos \\
\hline Escopo & $\begin{array}{l}\text { 1. Identificar questões relacionadas aos efeitos cumulativos significativos associados à } \\
\text { ação proposta e definir os objetivos de avaliação. } \\
\text { 2. Estabelecer o escopo geográfico para a análise. } \\
\text { 3. Estabelecer o prazo para a análise. } \\
\text { 4. Identificar outras ações que afetam os recursos, ecossistemas e comunidades humanas } \\
\text { (VECs ou Componentes Ambientais Valorizados) de preocupação. }\end{array}$ \\
\hline Descrição do ambiente afetado & $\begin{array}{l}\text { 5. Caracterizar os recursos, os ecossistemas e as comunidades humanas identificados no } \\
\text { escopo em relação a sua resposta a alterações e à capacidade de suportar estresse. } \\
\text { 6. Descrever as tensões que afetam estes recursos, ecossistemas e comunidades humanas } \\
\text { e sua relação aos limites regulatórios. } \\
\text { 7. Definir um estado inicial para os recursos, os ecossistemas e as comunidades } \\
\text { humanas. }\end{array}$ \\
\hline
\end{tabular}

FONTE: adaptado de Canter et al. (2013).

$2<$ http://www.epe.gov.br/Paginas/default.aspx>; $<$ http://www.aneel.gov.br>. 
TABELA 2 - Lista de Verificação para Análise da AAI da bacia do rio Teles Pires frente aos 12 passos do processo de avaliação de impactos cumulativos do Conselho Canadense

\begin{tabular}{|c|c|}
\hline $\begin{array}{c}\text { Processos básicos da Avaliação } \\
\text { de Impacto }\end{array}$ & Tarefas para realização da avaliação dos impactos cumulativos \\
\hline Escopo & $\begin{array}{l}\text { 1. Identificar as questões regionais de interesse. } \\
\text { 2. Selecionar VECs regionais apropriados. } \\
\text { 3. Identificar as fronteiras espaciais e temporais. } \\
\text { 4. Identificar outras ações que podem afetar os mesmos VECs. } \\
\text { 5. Identificar os impactos potenciais devido às ações e os possíveis efeitos. }\end{array}$ \\
\hline Análise dos efeitos & $\begin{array}{l}\text { 6. Completa coleta de dados de base regional. } \\
\text { 7. Avaliar efeitos da ação prevista nos VECs selecionados. } \\
\text { 8. Avaliar efeitos de todas as ações selecionadas nos VECs ou componentes ambientais } \\
\text { valorizados selecionados. }\end{array}$ \\
\hline Identificação da mitigação & 9. Medidas de mitigação recomendadas. \\
\hline Avaliação da significância & $\begin{array}{l}\text { 10. Avaliar a importância dos efeitos residuais. } \\
\text { 11. Comparar resultados com os limites para os objetivos de uso da terra e tendências. }\end{array}$ \\
\hline Acompanhamento & 12. Recomendar monitoramento regional e gestão de efeitos. \\
\hline
\end{tabular}

FONTE: Conselho Canadense (1999, como citado em Canter et al. 2013).

TABELA 3 - Lista de Verificação para Análise da AAI da bacia do rio Teles Pires frente ao VEC (Componente Ambiental Valorizado) direcionado ao processo de avaliação de impactos cumulativos em seis etapas

\section{Seis etapas do processo de avaliação de impactos cumulativos}

Etapa 1 - Iniciar o processo de avaliação e gestão dos efeitos cumulativos, identificando os efeitos diretos e indiretos incrementais do projeto proposto (ou política, plano ou programa) em VECs selecionados no entorno do local do projeto. Os VECs podem ser selecionados com base em informações relativas ao estágio atual ou futuro, com provável ocorrência de degradação de ambientes protegidos, espécies ou habitats, bem como com a presença de outras atividades humanas.

Etapa 2 - Ações passadas, presentes e futuras são razoavelmente previsíveis para identificar limites de espaço e tempo que contribuíram, contribuem ou podem contribuir para efeitos cumulativos (tensões) nos VECs mensurados por indicadores. Com base nesse conhecimento, procede-se à identificação adequada de limites de estudo espaciais e temporais para cada VEC.

Etapa 3 - Para os VECs selecionados, montar a informação adequada sobre os seus indicadores e descrever e avaliar o seu histórico de condições atuais e até mesmo projetadas. O histórico de informação deve coincidir com o limite temporal selecionado (isto é, um histórico a partir de um dado do ponto de referência).

Etapa 4 - "Conexão" do projeto proposto (ou plano, programa ou política) a outras ações na área de estudo de AIC considerando-se os VECs selecionados e seus indicadores, com ênfase aos efeitos incrementais sobre o componente ambiental valorizado, para cada efeito cumulativo associado aos VECs.

Etapa 5 - Avaliar a importância dos efeitos cumulativos em cada VEC dentro do horizonte de tempo estabelecido para o projeto. Tais determinações de significância devem começar com o incremento dos efeitos (diretos e indiretos) do projeto proposto ou ação em VECs específicos. O foco deve ser no VEC e não sobre o projeto ou ação. Critérios para tais determinações de significância já existem dentro dos sistemas de AIA em vários países, bem como em bancos de desenvolvimento e agências de ajuda (Conselho de Qualidade Ambiental, 1978, como citado em Canter et al., 2013). Além disso, o conceito de sustentabilidade ambiental (incluindo social e econômica) poderia ser considerado tanto em relação aos efeitos incrementais quanto aos cumulativos.

Etapa 6 - Para VECs em que se espera que estejam sujeitos ao incremento negativo de impactos do projeto proposto e para os quais os efeitos cumulativos são significativos, desenvolver medidas adequadas ou "medidas de mitigação" específicas da atividade para tais impactos. Além disso, se os efeitos cumulativos significativos são esperados em qualquer VEC, deve-se considerar a colaboração de múltiplas partes interessadas para desenvolver articulação nas medidas de gestão de efeitos em nível local ou regional ou ambos.

FONTE: Canter \& Ross (2010) como citado em Canter et al. (2013). 
Para avaliação dos procedimentos de AIC empregados na AAI da bacia do rio Teles Pires, foi realizada a análise na íntegra do conteúdo da AAI da bacia do rio Teles Pires (Empresa de Pesquisa Energética, 2009), cotejando a sua estrutura e o seu conteúdo às boas práticas de AIC estabelecidas nas Tabelas 1 a 3 .

\subsection{Análise dos impactos cumulativos nos EIAs}

Para analisar a associação dos impactos cumulativos da AAI aos impactos apresentados nos cinco EIAs inseridos nesta bacia, identificaram-se os impactos cumulativos e sinérgicos apresentados na AAI, que foram então confrontados aos impactos ambientais apresentados em cada um dos EIAs analisados. Para isso, utilizou-se o referencial de análise, conforme apresentado na Tabela 4.

\section{Resultados e discussão}

\subsection{Impactos ambientais e cumulativos apresentados na AAI e EIAs}

De acordo com a AAI da bacia do rio Teles Pires (Empresa de Pesquisa Energética, 2009), destacam-se como objetivos que nortearam os estudos de impactos cumulativos: desenvolver indicadores de sustentabilidade da bacia, com foco em recursos hídricos e energia; implementar a AAI com foco estratégico com os impactos ambientais avaliados para o conjunto de empreendimentos; analisar os efeitos sinérgicos da implantação dos empreendimentos hidrelétricos; identificar diretrizes socioambientais, compatilizar o uso e a conservação de recursos naturais; integrar a dimensão socioambiental da AAI ao processo de planejamento energético e articular esse processo de licenciamento ambiental de empreendimentos à gestão de recursos hídricos. Os estudos ambientais da AAI compreendem a caracterização socioambiental da bacia, a avaliação ambiental distribuída (AAD) e a análise dos principais conflitos em nível de bacia hidrográfica e a indicação das diretrizes para a realização da AAI. Os estudos são integrados e organizados nos seguintes componentes ambientais: recursos hídricos e ecossistemas aquáticos; meio físico e ecossistema terrestre e socioeconomia (Empresa de Pesquisa Energética, 2009). A Tabela 5 apresenta a síntese dos impactos cumulativos e sinérgicos da bacia do rio Teles Pires.

TABELA 4 - Associação entre impactos cumulativos e impactos ambientais nos instrumentos de avaliação de impacto na bacia do rio Teles Pires

\begin{tabular}{lll}
\hline $\begin{array}{c}\text { Categorias de associação verificadas entre os impactos } \\
\text { cumulativos e/ou sinérgicos (AAI) e os impactos } \\
\text { ambientais (EIA) }\end{array}$ & $\begin{array}{c}\text { Simbologia das } \\
\text { categorias }\end{array}$ & Racional \\
\hline $\begin{array}{l}\text { Há associação explícita e direta entre o impacto } \\
\text { cumulativo e/ou sinérgico e o(s) impacto(s) ambiental(is) }\end{array}$ & ++ & $\begin{array}{l}\text { O impacto no EIA é descrito e caracterizado } \\
\text { como o impacto cumulativo previsto na AAI }\end{array}$ \\
\hline $\begin{array}{l}\text { Pode-se inferir associação entre o impacto cumulativo e/ } \\
\text { ou sinérgico e o(s) impacto(s) ambiental(is) }\end{array}$ & + & $\begin{array}{l}\text { Há uma associação entre o impacto descrito } \\
\text { no EIA e o impacto cumulativo descrito na } \\
\text { AAI, mas essa associação é inferida }\end{array}$ \\
\hline $\begin{array}{l}\text { Não se verifica associação entre o impacto cumulativo } \\
\text { e/ou sinérgico e o(s) impacto(s) ambiental(is) }\end{array}$ & 0 & $\begin{array}{l}\text { Não há associação entre o impacto cumulati- } \\
\text { vo descrito na AAI e os impactos apesentados } \\
\text { no EIA }\end{array}$ \\
\hline
\end{tabular}

FONTE: Elaborado pelos autores. 
TABELA 5 - Relação dos impactos analisados na AAD por componente síntese para os efeitos cumulativos e sinérgicos na bacia do rio Teles Pires

\begin{tabular}{|c|c|c|}
\hline \multirow{2}{*}{$\begin{array}{c}\text { Impactos negativos analisados } \\
\text { na AAD }\end{array}$} & \multicolumn{2}{|c|}{ Efeito do impacto } \\
\hline & $\begin{array}{l}\text { Cumula- } \\
\text { tivo }\end{array}$ & $\begin{array}{l}\text { Sinér- } \\
\text { gico }\end{array}$ \\
\hline \multicolumn{3}{|c|}{ Recursos hídricos e ecossistemas aquáticos } \\
\hline Alteração do regime fluvial & $\mathrm{X}$ & $\mathrm{X}$ \\
\hline $\begin{array}{l}\text { Potencial de eutrofização dos } \\
\text { reservatórios }\end{array}$ & $\mathrm{X}$ & $\mathrm{X}$ \\
\hline $\begin{array}{l}\text { Perda de habitats específicos da } \\
\text { ictiofauna }\end{array}$ & $\mathrm{X}$ & $\mathrm{X}$ \\
\hline Contaminação por mercúrio & $\mathrm{X}$ & $\mathrm{X}$ \\
\hline \multicolumn{3}{|c|}{ Meio fisico e ecossistemas terrestres } \\
\hline Perda de áreas com potencial mineral & $\mathrm{X}$ & \\
\hline $\begin{array}{l}\text { Redução da cobertura vegetal e } \\
\text { fragmentação de ambientes }\end{array}$ & $\mathrm{X}$ & \\
\hline $\begin{array}{l}\text { Interferência da perda da vegetação } \\
\text { para a fauna silvestre associada }\end{array}$ & $\mathrm{X}$ & \\
\hline \multicolumn{3}{|l|}{ Socioeconomia } \\
\hline Perda de áreas produtivas & $\mathrm{X}$ & \\
\hline Alteração da estrutura fundiária & $\mathrm{X}$ & \\
\hline Pressão sobre a atenção à saúde & $\mathrm{X}$ & \\
\hline \multicolumn{3}{|l|}{ Impacto positivo analisado na AAD } \\
\hline \multicolumn{3}{|l|}{ Socioeconomia } \\
\hline Crescimento da arrecadação municipal & $\mathrm{X}$ & $\mathrm{X}$ \\
\hline
\end{tabular}

De acordo com EPE (2009), nos estudos do Inventário Hidrelétrico da Bacia do Rio Teles Pires realizados pela Eletrobras, em 2005, e aprovados pela Aneel, foi identificado um potencial de 3.697 MW nessa bacia por meio de seis aproveitamentos hidrelétricos. Desses aproveitamentos, cinco UHEs estavam em processo de licenciamento ambiental, por ocasião da apresentação da AAI, sendo que três - Sinop, Colíder e Foz do Apiacás -, por estarem inseridas apenas no Estado de Mato Grosso, foram licenciadas no âmbito do órgão ambiental desse estado, e duas UHEs - São Manoel e Teles Pires -, por afetarem dois estados, tiveram o licenciamento ambiental sob a responsabilidade do IBAMA. Além dessas 6 UHEs, existem 7 projetos de PCHs na bacia do rio Teles Pires que não foram analisados nesta pesquisa.

A UHE Teles Pires está localizada no Rio Teles Pires e tem potência instalada de $1.820 \mathrm{MW}$, reservatório com cerca de $70 \mathrm{~km}$ de extensão e 147,72 $\mathrm{km}^{2}$ nas áreas dos municípios de Jacareacanga-PA (16\% do reservatório) e Paranaíta-MT ( $84 \%$ do reservatório) (Empresa de Pesquisa Energética, 2010a). A UHE Foz do Apiacás (Empresa de Pesquisa Energética, 2010b) está situada na bacia hidrográfica do Alto Teles Pires, no rio Apiacás, principal afluente do rio Teles Pires. De acordo com os dados do EIA (Empresa de Pesquisa Energética, 2010b), a UHE, que se situa no Estado do Mato Grosso, foi projetada com potência instalada de $275 \mathrm{MW}$ e com reservatório de $89,60 \mathrm{~km}^{2}$. De acordo com os dados do EIA, a UHE São Manoel encontra-se no Estado do Mato Grosso e foi projetada com potência instalada de $746 \mathrm{MW}$ e com reservatório de 70,79 $\mathrm{km}^{2}$ (Empresa de Pesquisa Energética, 2009). De acordo com os dados do EIA da UHE Colíder, a hidrelétrica está inserida no Estado do Mato Grosso, foi projetada com potência instalada de $342 \mathrm{MW}$ e tem reservatório de 123,3 km² (Empresa de Pesquisa Energética, 2009). De acordo com os dados do EIA da UHE Sinop, esta hidrelétrica posiciona-se no Estado do Mato Grosso e foi projetada com potência instalada de $461 \mathrm{MW}$ e com reservatório de 329,60 $\mathrm{km}^{2}$ (JGP Consultoria e Participações Ltda., 2009).

A Tabela 6 apresenta os impactos sobre o meio físico, a Tabela 7 apresenta os impactos sobre o meio biótico e a Tabela 8 sobre o meio antrópico para os 5 EIAs. 
TABELA 6 - Impactos sobre o meio físico apresentados nos EIAs da UHE Teles Pires, UHE Foz do Apiacás, UHE São Manoel, UHE Colíder e UHE Sinop

\begin{tabular}{|c|c|c|c|c|}
\hline & UHE Foz do Apiacás & [E São Manoel & IE Colíder & UHE Sinop \\
\hline 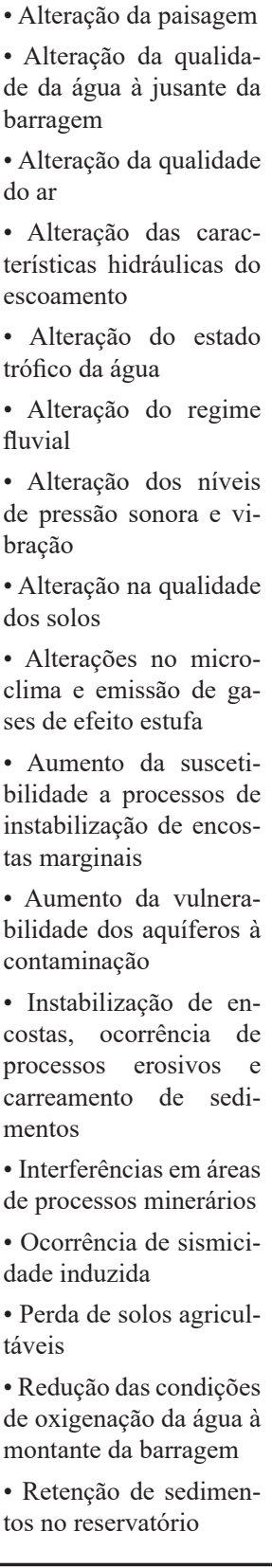 & $\begin{array}{l}\text { - Alteração da dinâmica } \\
\text { fluvial } \\
\text { - Alterações florísticas e } \\
\text { fisionômicas decorren- } \\
\text { tes da elevação do nível } \\
\text { do lençol freático } \\
\text { - Alterações microcli- } \\
\text { máticas } \\
\text { - Início e/ou aceleração } \\
\text { de processos erosivos e } \\
\text { instabilização de encos- } \\
\text { tas marginais do reser- } \\
\text { vatório } \\
\text { - Interferência com ati- } \\
\text { vidades e processos mi- } \\
\text { nerários } \\
\text { - Interferência com o pa- } \\
\text { trimônio paleontológico } \\
\text { - Interferência na dinâ- } \\
\text { mica do aquífero e no } \\
\text { nível do lençol freático } \\
\text { - Ocorrência de sismos } \\
\text { induzidos (tremores de } \\
\text { terra) }\end{array}$ & $\begin{array}{l}\text { - Aumento da suscetibili- } \\
\text { dade a processos de ins- } \\
\text { tabilização de encostas } \\
\text { marginais } \\
\text { - Aumento da vulnera- } \\
\text { bilidade dos aquíferos à } \\
\text { contaminação } \\
\text { - Instabilização de en- } \\
\text { costas, ocorrência de } \\
\text { processos erosivos e car- } \\
\text { reamento de sedimentos } \\
\text { - Interferência em áreas } \\
\text { de processos minerários } \\
\text { - Ocorrência de sismici- } \\
\text { dade induzida } \\
\text { - Perda de solos agricul- } \\
\text { turáveis } \\
\text { - Retenção de sedimen- } \\
\text { tos no reservatório }\end{array}$ & $\begin{array}{l}\text { - Alteração do risco de } \\
\text { contaminação do solo du- } \\
\text { rante as obras } \\
\text { - Alteração na qualidade do } \\
\text { ar durante as obras } \\
\text { - Alterações na qualidade } \\
\text { da água durante as obras } \\
\text { - Alterações no clima local } \\
\text { - Alterações no regime flu- } \\
\text { viométrico e na qualidade } \\
\text { da água durante o enchi- } \\
\text { mento do reservatório } \\
\text { - Assoreamento de reman- } \\
\text { sos e confluências } \\
\text { - Assoreamento durante a } \\
\text { fase construtiva } \\
\text { - Criação de áreas úmidas } \\
\text { permanentes } \\
\text { - Elevação do nível do len- } \\
\text { çol freático após a forma- } \\
\text { ção do reservatório } \\
\text { - Formação de ambiente } \\
\text { lêntico e alterações das } \\
\text { propriedades físicas, quí- } \\
\text { micas e biológicas das } \\
\text { águas superficiais na fase } \\
\text { de operação } \\
\text { - Indução de processos ero- } \\
\text { sivos durante as obras } \\
\text { - Instabilização de margens } \\
\text { e indução de processos } \\
\text { eroses na geometria fluvial à } \\
\text { jusante do barramento } \\
\text { durante a operação } \\
\text { - Ocorrência de sismos in- } \\
\text { duzidos }\end{array}$ & 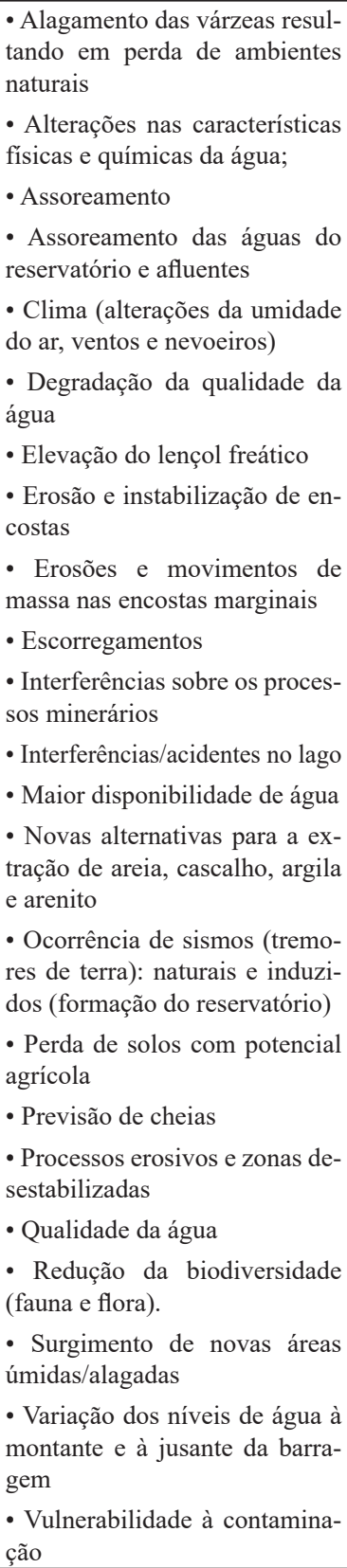 \\
\hline
\end{tabular}

FONTE: Adaptado de Empresa de Pesquisa Energética (2009; 2010b; 2011); JGP Consultoria e Participações Ltda. (2009) e Themag (2010). 
TABELA 7 - Impactos sobre o meio biótico apresentados nos EIAs da UHE Teles Pires, UHE Foz do Apiacás, UHE São Manoel, UHE Colíder e UHE Sinop

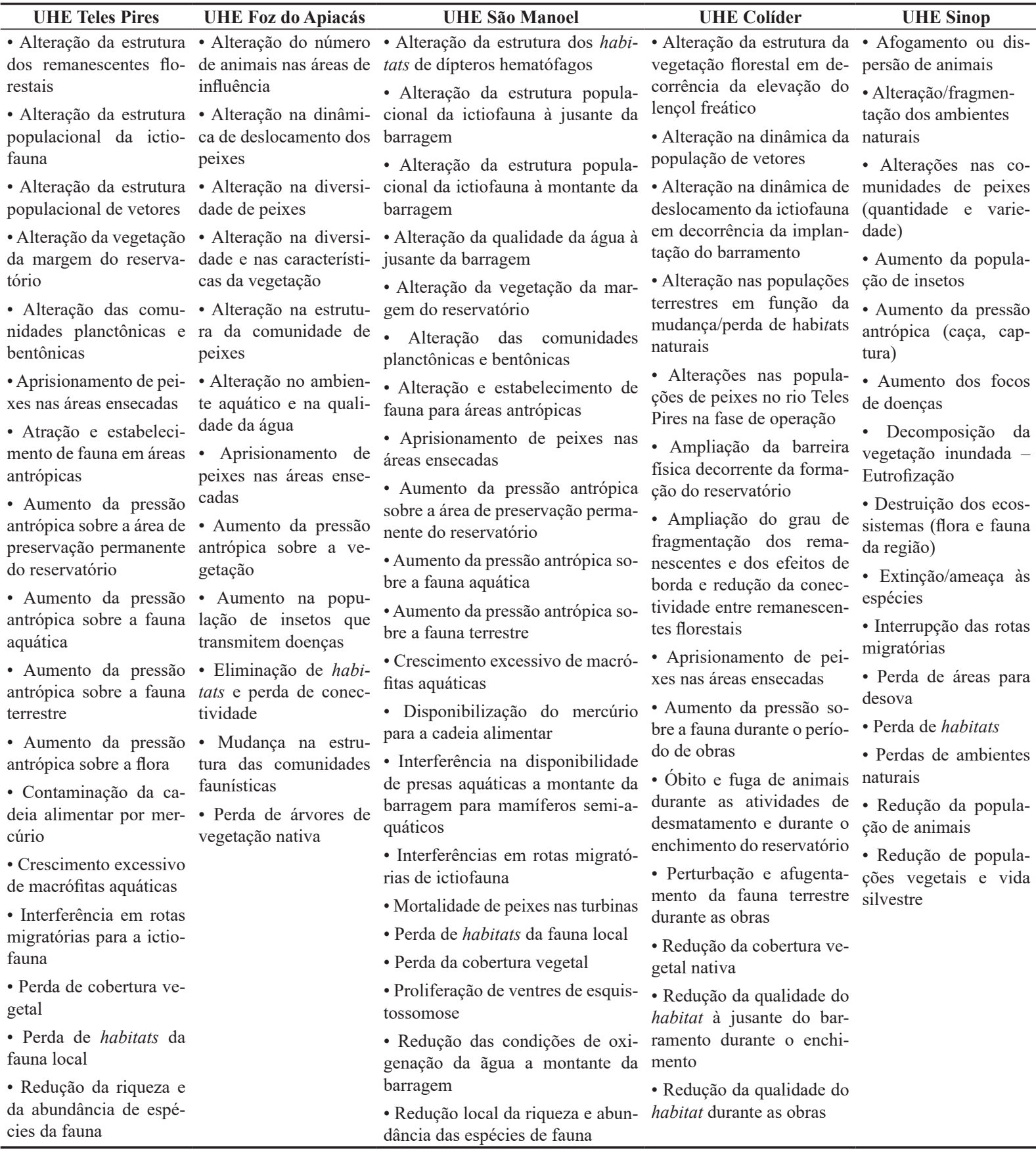

FONTE: Adaptado de Empresa de Pesquisa Energética (2009; 2010b; 2011); JGP Consultoria e Participações Ltda. (2009) e Themag (2010). 
TABELA 8 - Impactos sobre o meio antrópico apresentados nos EIAs da UHE Teles Pires, UHE Foz do Apiacás, UHE São Manoel, UHE Colíder e UHE Sinop

\begin{tabular}{|c|c|c|c|c|}
\hline UHE Teles Pires & UHE Foz do A & UHE São Mar & UHE CC & UHE Sinop \\
\hline $\begin{array}{l}\text { - Alteração do sistema } \\
\text { viário } \\
\text { - Aumento da demanda } \\
\text { por serviços públicos e } \\
\text { pressão sobre a infraes- } \\
\text { trutura } \\
\text { - Alteração da dinâmica } \\
\text { demográfica } \\
\text { - Ampliação do conhe- } \\
\text { cimento técnico-cien- } \\
\text { tífico } \\
\text { - Aumento da incidên- } \\
\text { cia e disseminação de } \\
\text { doenças } \\
\text { - Aumento da ocor- } \\
\text { rência de acidentes de } \\
\text { trabalho } \\
\text { - Aumento da prosti- } \\
\text { tuição } \\
\text { - Dinamização da eco- } \\
\text { nomia } \\
\text { - Elevação das receitas } \\
\text { públicas municipais } \\
\text { - Geração de empregos } \\
\text { - Geração de expectati- } \\
\text { vas na população } \\
\text { - Interferência em sítios } \\
\text { com presença de ele- } \\
\text { mentos do patrimônio } \\
\text { cultural, histórico e ar- } \\
\text { queológico }\end{array}$ & $\begin{array}{l}\text { - Alteração na infraestru- } \\
\text { tura viária } \\
\text { - Alteração na paisagem } \\
\text { - Alteração no cotidiano } \\
\text { da população } \\
\text { - Alteração no uso e na } \\
\text { ocupação do solo } \\
\text { - Aumento na disponibi- } \\
\text { lidade de energia elétrica } \\
\text { no sistema } \\
\text { - Criação de expectativas } \\
\text { desfavoráveis } \\
\text { - Criação de expectativas } \\
\text { favoráveis } \\
\text { - Dinamização da eco- } \\
\text { nomia } \\
\text { - Emissões de gases de } \\
\text { efeito estufa (GEE) } \\
\text { - Interferências com o } \\
\text { patrimônio arqueológico } \\
\text { - Interferências com o } \\
\text { patrimônio histórico, cul- } \\
\text { tural e paisagístico } \\
\text { - Pressão na infraestrutu- } \\
\text { ra de serviços }\end{array}$ & $\begin{array}{l}\text { - Aumento da prostituição } \\
\text { - Alteração da dinâmica } \\
\text { demográfica } \\
\text { - Ampliação do conheci- } \\
\text { mento técnico-científico } \\
\text { - Aumento da demanda por } \\
\text { serviços públicos e pressão } \\
\text { sobre a infraestrutura } \\
\text { - Aumento da incidência } \\
\text { de doenças } \\
\text { - Aumento da ocorrência } \\
\text { de acidentes de trabalho } \\
\text { - Dinamização da eco- } \\
\text { nomia } \\
\text { - Geração de empregos } \\
\text { - Geração de expectativas } \\
\text { na população } \\
\text { - Incremento das receitas } \\
\text { públicas } \\
\text { - Interferência com sítios } \\
\text { com presença de elemen- } \\
\text { tos de patrimônio cultural, } \\
\text { histórico e arqueológico } \\
\text { - Melhoria do sistema } \\
\text { viário } \\
\text { - Mobilização da socie- } \\
\text { dade civil } \\
\text { - Modificação das con- } \\
\text { dições atuais de extração } \\
\text { mineral }\end{array}$ & $\begin{array}{l}\text { - Aumento da demanda por serviços de saúde } \\
\text { - Aumento da massa salarial } \\
\text { - Aumento das receitas fiscais } \\
\text { - Dinamização das economias locais duran- } \\
\text { te a construção } \\
\text { - Geração de empregos diretos e indiretos } \\
\text { durante a construção e operação } \\
\text { - Geração de expectativas da população so- } \\
\text { bre a obra } \\
\text { - Incômodos à população devido ao tráfe- } \\
\text { go pesado e a alterações em estradas rurais, } \\
\text { acessos e travessias } \\
\text { - Indução ao crescimento e alterações nos } \\
\text { padrões de uso do solo urbanos } \\
\text { - Interferência com a pesca } \\
\text { - Interferências com áreas e atividades de } \\
\text { lazer da população local } \\
\text { - Interferências com atividades turísticas } \\
\text { - Obstrução de estradas vicinais pelo reserva- } \\
\text { tório e interferência com redes de utilidades } \\
\text { - Perda de áreas de produção agrossilvopastoril } \\
\text { - Perda de moradias e fontes de rendimento } \\
\text { - Pressões indiretas sobre as infraestruturas } \\
\text { e os serviços públicos urbanos } \\
\text { - Retração econômica ao final da fase de } \\
\text { construção } \\
\text { - Risco de indução de endemias em decor- } \\
\text { rência da formação do reservatório } \\
\text { - Risco de perda de sítios e bens de interesse } \\
\text { cultural } \\
\text { - Risco de tensões entre mão de obra e locais } \\
\text { - Riscos à saúde pública durante a construção } \\
\text { - Saldos migratórios negativos ao final da } \\
\text { construção } \\
\text { - Substituição de usos nas áreas de interven- } \\
\text { ção e inundação } \\
\text { - Indução de alterações nos padrões de uso } \\
\text { vatura do solo no entorno do reser- } \\
\text { a }\end{array}$ & $\begin{array}{l}\text { - Alteração da paisagem (pela } \\
\text { formação do lago) } \\
\text { - Alteração e/ou destruição do } \\
\text { patrimônio arqueológico e his- } \\
\text { tórico } \\
\text { - Alterações nas atividades de } \\
\text { turismo e lazer pela formação } \\
\text { do reservatório } \\
\text { - Ampliação da oferta de ener- } \\
\text { gia elétrica no sistema } \\
\text { - Atividades econômicas afetadas } \\
\text { - Aumento da arrecadação/ } \\
\text { recursos disponíveis - ISS e } \\
\text { ICMS } \\
\text { - Aumento na incidência de en- } \\
\text { fermidades } \\
\text { - Aumento nos níveis de empre- } \\
\text { go e renda e nas receitas muni- } \\
\text { cipais } \\
\text { - Compensação financeira } \\
\text { (royalties) } \\
\text { - Comprometimento do patri- } \\
\text { mônio cultural } \\
\text { - Conflitos entre municipalida- } \\
\text { des e empreendedor } \\
\text { - Desinformação, incertezas so- } \\
\text { bre o empreendimento (a serem } \\
\text { reduzidas) } \\
\text { - Deslocamento compulsório de } \\
\text { população rural } \\
\text { - Desorganização institucional, } \\
\text { administrativa e de gestão dos } \\
\text { municípios em nível regional } \\
\text { - Doenças, epidemias e óbitos } \\
\text { nos municípios } \\
\text { - Efeitos sobre as finanças pú- } \\
\text { blicas (benéficos) } \\
\text { - Exclusão/desinformação (a } \\
\text { ser reduzida pela sensibilização, } \\
\text { educação e formação do público } \\
\text { escolar e comunidade em geral); }\end{array}$ \\
\hline
\end{tabular}

FONTE: Adaptado de Empresa de Pesquisa Energética (2009; 2010b; 2011); JGP Consultoria e Participações Ltda. (2009) e Themag (2010). 


\subsection{Análise da Avaliação Ambiental Integrada da bacia do rio Teles Pires}

As Tabelas 9, 10 e 11 cotejam a análise da AAI da bacia do rio Teles Pires às boas práticas de Avaliação de Impactos Cumulativos.

Com relação à Tabela 9, observa-se que quan-

to ao escopo não foram atendidas as premissas de identificar outras ações presentes ou futuras na bacia que podem ocorrer ou sofrer os efeitos da implantação do conjunto de hidrelétricas. A análise ficou restrita à implantação dos empreendimentos hidrelétricos UHEs e PCHs. Os demais dez passos foram realizados na AAI da bacia do rio Teles Pires.

TABELA 9 - Análise da AAI Teles Pires frente aos 11 passos para a AIC descritos na Tabela 1

Componentes da Avaliação de Impacto

Escopo

\section{Avaliação Ambiental Integrada da bacia do rio Teles Pires}

1. As questões relacionadas aos efeitos cumulativos significativos foram analisadas com relação à ação proposta pela integração entre as dinâmicas sociais, políticas e econômicas identificadas na utilização dos recursos naturais da bacia do rio Teles Pires e nos conflitos resultantes pela implantação dos empreendimentos hidrelétricos, como poderiam ser agravados ou gerados.

2. O escopo geográfico da análise foi definido compreendendo os limites da bacia hidrográfica, que por sua vez foi caracterizada em termos de classes de fragilidade.

3. Foi realizada uma análise prospectiva para cenários atuais e futuros em um horizonte de 10 anos entre os mesmos.

4. Não foram identificadas outras ações presentes ou futuras na bacia que podem surtir ou sofrer os efeitos da implantação do conjunto de hidrelétricas. A análise ficou restrita à implantação dos empreendimentos hidrelétricos UHEs e PCHs.

5. Foram caracterizados os recursos, os ecossistemas e as comunidades humanas identificadas em uma análise denominada análise socioambiental da bacia hidrográfica.

Descrevendo o ambiente afetado

6. As tensões que afetam esses recursos foram caracterizadas em termos de fragilidade dos recursos naturais na bacia hidrográfica e dos conflitos resultantes. A relação com os limites regulatórios foi estabelecida pelos políticas, planos e programas em níveis federal e estadual que incidem na bacia hidrográfica.

7. Foi caracterizado o estado inicial dos recursos naturais, ecossistemas e comunidades humanas, para os quais foram estabelecidos indicadores em termos de fragilidades e potencialidades.

8. Na análise, foram identificadas as relações de causa e as consequências entre as atividades humanas e os recursos naturais, os ecossistemas e as comunidades, mas prioritariamente relacionadas às atividades de implantação das hidrelétricas.

Determinando as consequências ambientais
9. Os efeitos cumulativos foram classificados em termos de natureza, duração, abrangência e efeitos quanto à sinergia ou cumulativismo.

10. São apontadas recomendações para mitigação dos efeitos cumulativos no processo de licenciamento ambiental de empreendimentos hidrelétricos e da gestão da bacia hidrográfica.

11. Foram identificados indicadores que permitem monitorar e eventualmente adaptar as alternativas e/ou soluções visando atenuar os impactos cumulativos.

FONTE: Elaborada pelos autores. 
TABELA 10 - Análise da AAI da bacia do rio Teles Pires frente aos 12 passos do processo de avaliação de impactos cumulativos descritos na Tabela 2

\begin{tabular}{|c|c|}
\hline $\begin{array}{l}\text { Processos básicos da } \\
\text { Avaliação de Impacto }\end{array}$ & Avaliação Ambiental Integrada da bacia do rio Teles Pires \\
\hline \multirow{5}{*}{ Escopo } & 1. As questões regionais de interesse foram identificadas por meio da análise socioambiental da bacia hidrográfica. \\
\hline & 2. Os componentes ambientais em termos da bacia hidrográfica foram apresentados. \\
\hline & $\begin{array}{l}\text { 3. As fronteiras espaciais da análise ficaram restritas aos limites da bacia, sem analisar se as repercussões da aná- } \\
\text { lise poderiam extrapolar a bacia. A análise temporal foi apresentada na condição atual, sem os empreendimentos, } \\
\text { e projetada para um cenário futuro de } 10 \text { anos, com os empreendimentos executados. }\end{array}$ \\
\hline & $\begin{array}{l}\text { 4. Somente foram caracterizadas as ações das hidrelétricas, embora na caracterização dos conflitos tenham sido } \\
\text { identificados atores e agentes envolvidos. }\end{array}$ \\
\hline & $\begin{array}{l}\text { 5. Foram identificados os impactos cumulativos e sinérgicos que serão gerados pelas ações das hidrelétricas pro- } \\
\text { jetadas na bacia hidrográfica. }\end{array}$ \\
\hline \multirow[b]{3}{*}{ Análise dos efeitos } & 6. Foi realizada uma ampla coleta de dados em base regional nos limites da bacia hidrográfica. \\
\hline & $\begin{array}{l}\text { 7. Os efeitos da implantação dos empreendimentos hidrelétricos no interior da bacia hidrográfica foram detalha- } \\
\text { damente analisados. }\end{array}$ \\
\hline & $\begin{array}{l}\text { 8. Apenas os efeitos da implantação dos empreendimentos hidrelétricos no interior da bacia hidrográfica foram } \\
\text { detalhadamente analisados. Outras ações eventualmente previstas na bacia e que teriam efeito sobre os compo- } \\
\text { nentes ambientais valorizados não foram contempladas nessa análise, embora alguns efeitos decorrentes dessas } \\
\text { ações, como, por exemplo, do mercúrio oriundo das atividades de garimpo, tenham sido discutidos. }\end{array}$ \\
\hline $\begin{array}{l}\text { Identificação da miti- } \\
\text { gação }\end{array}$ & $\begin{array}{l}\text { 9. São apontadas recomendações para mitigação dos efeitos cumulativos no processo de licenciamento ambiental } \\
\text { de empreendimentos hidrelétricos e da gestão da bacia hidrográfica. }\end{array}$ \\
\hline \multirow{2}{*}{$\begin{array}{l}\text { Avaliação da signifi- } \\
\text { cância }\end{array}$} & 10.Os efeitos residuais dos impactos cumulativos e sinérgicos são discutidos. \\
\hline & $\begin{array}{l}\text { 11. É apresentada uma análise sucinta em termos dos impactos cumulativos e sinérgicos residuais e suas repercus- } \\
\text { sões sobre o ambiente local. Entretanto, os objetivos do uso do solo e as tendências não são enfatizados. }\end{array}$ \\
\hline Acompanhamento & $\begin{array}{l}\text { 12. Foram identificados indicadores que permitem monitorar e eventualmente adaptar as alternativas e/ou solu- } \\
\text { ções visando atenuar os impactos cumulativos. }\end{array}$ \\
\hline
\end{tabular}

FONTE: Elaborada pelos autores.

Com relação à Tabela 10 , observa-se que, quanto ao escopo, somente foram consideradas as ações das hidrelétricas, embora na caracterização dos conflitos tenham sido identificados atores e agentes envolvidos. Quanto à análise dos efeitos, limitou-se a detalhar aqueles referentes à implantação dos empreendimentos hidrelétricos no interior da bacia hidrográfica. Outras ações eventualmente previstas na bacia e que teriam efeito sobre os componentes ambientais valorizados não foram contempladas nessa análise, embora alguns efeitos decorrentes dessas ações, como, por exemplo, do mercúrio oriundo das atividades de garimpo, tenham sido discutidos. Quanto à avaliação da significância, é apresentada uma análise sucinta em termos dos impactos cumulativos e sinérgicos residuais e suas repercussões sobre o ambiente local. Entretanto, os objetivos do uso do solo e as tendências não são enfatizados. Os demais passos foram contemplados na AAI da bacia do rio Teles Pires.

Com relação à Tabela 11, as etapas 2,4 e 6 não foram totalmente realizadas na AAI da bacia do rio Teles Pires. A principal limitação refere-se à não consideração ampla de outras ações que não a dos empreendimentos hidrelétricos projetados na bacia hidrográfica. 
TABELA 11 - Análise da AAI da bacia do rio Teles Pires frente ao VEC (Componente Ambiental Valorizado) direcionado ao processo de avaliação de impactos cumulativos em seis etapas, conforme descritas na Tabela 3

Seis etapas do processo de avaliação de impactos cumulativos na AAI da bacia do rio Teles Pires.

\begin{abstract}
Etapa 1 - O processo de Avaliação e gestão dos efeitos cumulativos (CEAM) foi realizado a partir dos efeitos cumulativos e sinérgicos discutidos para componentes ambientais selecionados na bacia hidrográfica. Os componentes ambientais Análise: realizada. foram analisados com base em indicadores propostos para um cenário atual (sem os empreendimentos na bacia) e outro futuro (com os empreendimentos).
\end{abstract}

Etapa 2 - Foi realizada a análise das características socioambientais atuais da bacia, o que engloba as passadas e presentes, mas sem ênfase em ações que não estejam vinculadas aos aproveitamentos hidrelétricos. Foram melhor caracterizadas as ações futuras referentes aos aproveitamentos hidrelétricos no tempo e no espaço, mas quanto a outras ações na bacia essa análise não foi realizada.

Análise: parcialmente realizada, pois focou nos empreendimentos hidrelétricos na bacia hidrográfica. As ações não enquadradas nesse escopo não foram analisadas e em algumas análises foram mencionadas, porém não amplamente quanto a sua localização no tempo e no espaço como as dos empreendimentos hidrelétricos.

Etapa 3 - Os componentes ambientais selecionados foram analisados por meio de indicadores nos cenários atual e futuro, com a implantação dos empreendimentos hidrelétricos. O quadro de políticas, planos e programas associados à bacia Análise: realizada. também foi considerado.

Etapa 4 - As hidrelétricas propostas foram analisadas em termos de sua reali-
zação na bacia e discutidas repercussões das políticas, planos e programas nesse
contexto. Entretanto, outras ações na bacia que podem afetar os componentes
ambientais valorizados não foram discutidas. Essa análise foi feita baseada em
indicadores e na identificação de conflitos socioambientais. Análise: parcialmente realizada, pois ficou direcionada aos empreendimentos hidrelétricos, desconsiderando outras eventuais ações que possam concorrer na bacia hidrográfica e afetar os recursos, os ecossistemas e a sociedade.

Etapa 5 - A importância dos efeitos cumulativos nos componentes ambientais valorizados ao longo do horizonte de tempo estabelecido para a implantação dos empreendimentos hidrelétricos foi analisada. Como preconizado pela avaliação Análise: realizada. de impactos cumulativos, o foco refere-se ao componente ambiental valorizado e não às ações dos empreendimentos.

Etapa 6 - Foram identificados indicadores que permitem monitorar e eventualmente adaptar as alternativas e/ou soluções visando atenuar os impactos cumulativos. Não estão detalhadas as medidas de mitigação, embora os conflitos tenham Análise: parcialmente realizada. sido identificados, os impactos residuais também, bem como as políticas, os planos e os programas associados.

FONTE: Elaborada pelos autores.

Analisando-se as Tabelas 9 a 11, que sintetizam as boas práticas de AIC para bacias hidrográficas, considera-se que, à exceção das boas práticas referentes à consideração ampla de outras ações além das hidrelétricas projetadas na bacia hidrográfica, as demais foram consideradas. Desse modo, considera-se que o primeiro pressuposto estabelecido - "evidências de boas práticas de avaliação de impactos cumulativos são encontradas na AAI" foi verificado na pesquisa. Essa constatação permite reforçar um dos benefícios possíveis da AIC, como relatados por Cooper \& Sheate (2004): que o uso do instrumento permite reduzir a contribuição incremental de impactos cumulativos em dada região, no caso a bacia hidrográfica, antecipando-os no processo de planejamento.

Noble et al. (2011) enfatizam o consenso de que a prática de AIC deve abranger não somente projetos individuais, em escala regional remetendo a bacias hidrográficas, ensejando uma série de de- 
safios com esta finalidade. Importante salientar que esses autores destacam alguns desafios para avançar na AIC em bacias hidrográficas que foram observados nessa análise, como a concordância acerca da natureza e definição dos impactos ambientais cumulativos; a escala de análise; indicadores de monitoramento para avaliação e gerenciamento dos impactos cumulativos nas bacias hidrográficas.

Porém, o fato de que nem todas as boas práticas de AIC são encontradas na AAI confirma o salientado por Seitz et al. (2011, p. 172), que, dada a maneira aditiva e sinérgica como os impactos têm afetado bacias hidrográficas por aproveitamentos múltiplos, a avaliação de impactos cumulativos deve ser melhorada para captar essas transformações de maneira mais abrangente, resguardando os potenciais usos múltiplos das bacias hidrográficas.

\subsection{Análise dos impactos cumulativos dos EIAs inseridos na bacia do rio Teles Pires}

A Tabela 12 e a Tabela 13 apresentam, respectivamente, os impactos ambientais contidos nos cinco Estudos de Impacto Ambiental (EIA) realizados na bacia hidrográfica e a análise dos impactos cumulativos apresentados na AAI com relação aos impactos de cada um dos EIAs.
Pela Tabela 12, observa-se que, à exceção da UHE Foz dos Apiacás, praticamente há o mesmo número de impactos ambientais identificados nas demais UHEs. A análise da Tabela 6, da Tabela 7 e da Tabela 8 permite considerar que a caracterização dos impactos apresentados nos EIAs é muito semelhante, independente do número absoluto de impactos em cada EIA. Os dados das Tabelas 6 a 8 foram cotejados aos dados da Tabela 5, como apresentado na Tabela 13.

Pela análise da Tabela 13, pode-se considerar que, dos impactos cumulativos descritos na AAI:

- aqueles com menor associação nos EIAs são: Potencial de eutrofização dos reservatórios e contaminação por mercúrio (com 3 associações com "0"); Perda de áreas com potencial mineral; Perda de áreas produtivas, pressão sobre atenção à saúde e Crescimento de arrecadação municipal (com 1 associação com "0").

- aqueles impactos com maior associação nos EIAs são: Redução da cobertura vegetal e fragmentação de ambientes; Interferência da perda de vegetação para a fauna silvestre associada; Perda de áreas produtivas (com 4 associações com “++").

TABELA 12 - Impactos ambientais apresentados nos EIAs das UHEs situadas na bacia do rio Teles Pires

\begin{tabular}{cccccc}
\hline \multicolumn{5}{c}{ Número de impactos ambientais significativos apresentados nos EIAs } \\
\hline Meio & UHE Teles Pires & UHE Colíder & UHE Sinop & UHE Foz dos Apiacás & UHE São Manoel \\
\hline Físico & 17 & 15 & 23 & 8 & 14 \\
Biótico & 17 & 14 & 15 & 12 & 21 \\
Antrópico & 20 & 29 & 23 & 12 & 22 \\
Total de impactos & 54 & 58 & 61 & 32 & 57 \\
\hline
\end{tabular}

FONTE: Elaborada pelos autores. 
TABELA 13 - Análise dos impactos cumulativos da AAI com relação a cada um dos EIAs inseridos na bacia hidrográfica do rio Teles Pires

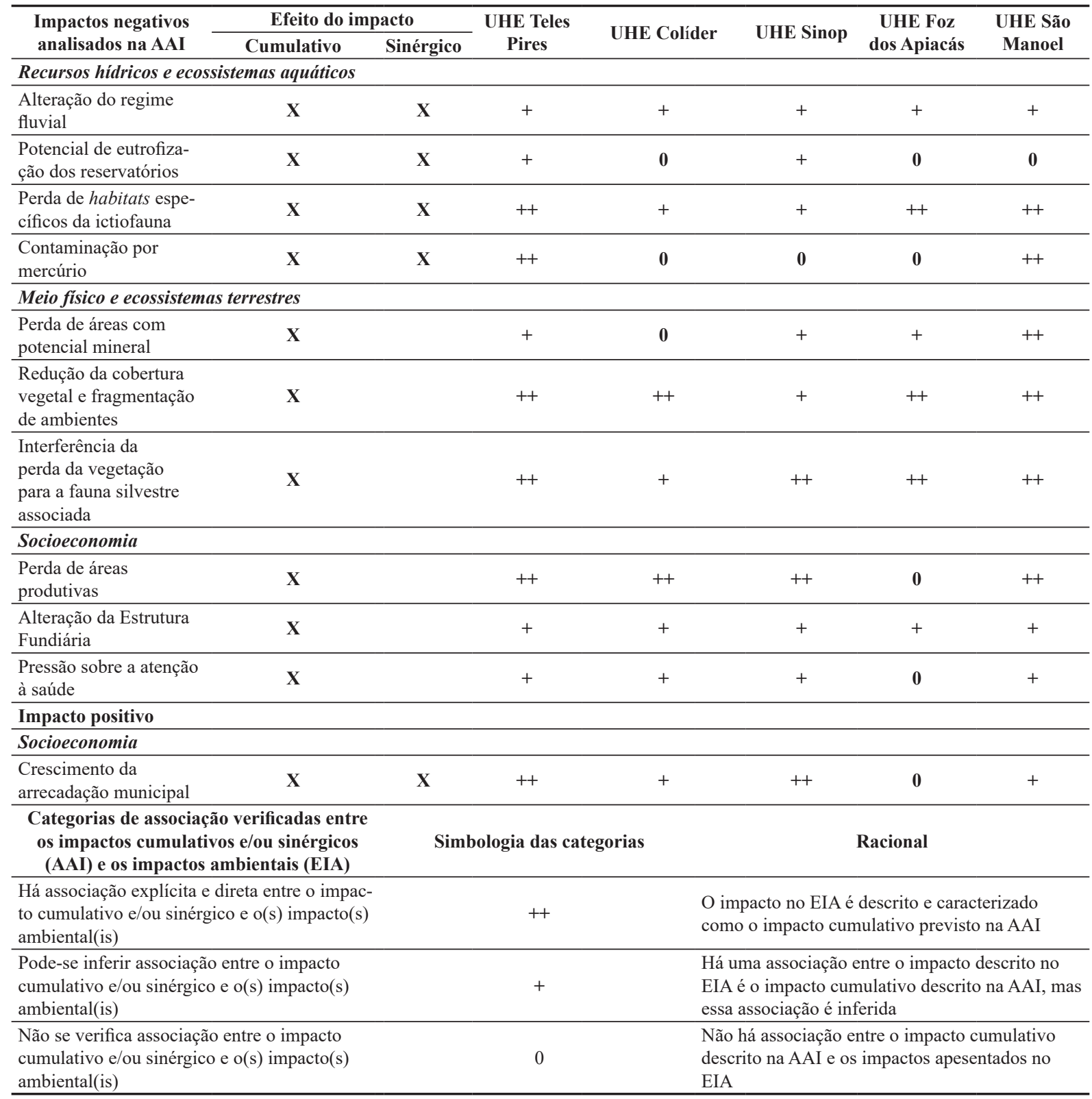

FONTE: Elaborado pelos autores. 
Pelos resultados da Tabela 13, considerando-se as categorias de associação entre os impactos cumulativos e/ou sinérgicos apresentados na AAI e nos EIAs, observa-se que, de um total possível de 50 associações, foram constatadas: 20 para "há associação explícita e direta entre o impacto cumulativo e/ou sinérgico e o(s) impacto(s) ambiental(is)"; 25 para "pode-se inferir associação entre o impacto cumulativo e/ou sinérgico e o(s) impacto(s) ambiental(is)"; 10 para "não se verifica associação entre o impacto cumulativo e/ou sinérgico e o(s) impacto(s) ambiental(is)". Assim, 63,6\% dos impactos cumulativos ou não estão associados aos impactos ambientais dos EIAs ou apenas podem ser inferidos. Desse modo, considera-se que a análise dos impactos cumulativos realizada na AAI não está plenamente associada à análise de impactos ambientais apresentadas nos EIAs da bacia hidrográfica do rio Teles Pires.

Ainda de acordo com a Tabela 13, dentre os EIAs analisados, o da UHE Teles Pires, seguido pelo EIA da UHE São Manoel, apresentaram as frequências maiores para associações explícitas, mesmo assim, pouco superiores a 50\%. Por outro lado, nessa categoria de associação explícita, os EIAs da UHE Colíder, UHE Foz dos Apiacás e UHE Sinop e UHE Colíder apresentam as menores frequências observadas. Entretanto, os EIAs da UHE Sinop e UHE Colíder superam a frequência de associações inferidas em relação ao EIA Foz dos Apiacás. Alguns impactos cumulativos descritos na AAI foram melhor contemplados em alguns EIAs, por vezes caracterizados em apenas um impacto ou por uma associação de impactos, inclusive em meios diferentes (por exemplo, físico e biótico). Desse modo, considerados os EIAs individualmente, verifica-se que a análise de impactos cumulativos da AAI não se representou de modo abrangente nos estudos ambientais das hidrelétricas.
Considera-se, assim, que o segundo pressuposto estabelecido - "os impactos cumulativos em nível de empreendimentos hidrelétricos não são adequadamente considerados, mesmo em casos em que há avaliação de impactos cumulativos em bacias hidrográficas" - também foi verificado na pesquisa. Embora os impactos cumulativos em nível de bacia hidrográfica tenham sido caracterizados, esses impactos não foram totalmente inseridos nos EIAs dos empreendimentos hidrelétricos. Tais achados se coadunam aos discutidos por Westin et al. (2014, p. 759), que analisaram a expansão das hidrelétricas nas bacias dos rios Araguaia e Tapajós e destacaram que os resultados das AAIs, se melhor considerados nos EIAs, "poderiam realmente colaborar com o processo de licenciamento ambiental, tornando sua contribuição mais efetiva para o processo de tomada de decisão para as várias partes interessadas na bacia hidrográfica".

Como bem destacado por Gunn \& Noble (2011), muitos autores consideram limitado o uso da AIC para projetos e que os efeitos cumulativos são melhor avaliados em contexto regional ou estratégico. Nesta pesquisa, verificou-se que os impactos cumulativos em nível estratégico não foram bem avaliados em nível de projeto.

Os achados dessa pesquisa em parte comprovam ainda o estabelecido por Bidstrup et al. (2016, p. 157), que "[...] avaliação de impactos cumulativos é um elemento essencial na avaliação de impacto que vem sendo mal executado no mundo inteiro"; quanto à análise em nível de projeto, entretanto, refutam para a análise em nível de bacia hidrográfica.

Uma maior efetividade na identificação e na integração de impactos cumulativos em âmbito de projeto poderia estar fundamentada nas recomendações de Dibo et al. (2012) acerca da necessidade de estabelecimento de requisitos, métodos e procedimentos para o uso dessa abordagem em estudos ambientais de projetos individuais. 
Incluir os impactos cumulativos na agenda de tomada de decisão das hidrelétricas passa além de simplesmente reproduzir os impactos dessa categoria identificados em nível de bacia. Joseph et al. (2017), de modo a superar esses obstáculos, estabeleceram a partir da experiência no Canadá que algumas ações adicionais à prática tradicional de AIA devem ser realizadas para incorporar os impactos cumulativos nesse nível de avaliação, considerando-se as seguintes etapas: 1) escopo dos componentes valorizados, indicadores e limiares de significância; 2) avaliação dos efeitos cumulativos a partir do diagnóstico ambiental; 3) avaliar e caracterizar efeitos cumulativos do projeto e de outras fontes; 4) avaliar a significância dos impactos cumulativos; 5) distinguir as contribuições relativas das fontes de efeitos; 6) explorar medidas adicionais; 7) consolidar os resultados finais da análise de efeitos cumulativos.

Segundo Porto \& Tucci (2009), a AAI deve orientar a elaboração dos EIAs quanto à incorporação e à análise desses impactos cumulativos em nível de empreendimentos hidrelétricos. Entretanto, essa sequência de etapas não permeou a elaboração dos estudos técnicos ambientais individuais, perdendo-se uma oportunidade de auferir amplamente os benefícios do tiering ou encadeamento (Turco \& Gallardo, no prelo; Fonseca et al., 2017; Sánchez \& Silva-Sánchez, 2008). Como a tomada de decisão dá-se em nível de projetos, considera-se que um conteúdo de EIA que vise lidar com os impactos cumulativos deveria contemplar essas orientações.

\section{Conclusões}

O setor de planejamento de energia hidrelétrica é reconhecido por causar uma série de impactos ambientais significativos e negativos, sobretudo na região amazônica brasileira, mas, ao mesmo tempo, é notável que seja um dos pioneiros na utilização e na ampliação do escopo dos instrumentos de avaliação de impacto. A partir dos estudos de avaliação de impactos aplicados à bacia hidrográfica do rio Teles Pires, na Amazônia, considera-se que o instrumento da Avaliação Ambiental Integrada permite analisar os impactos cumulativos no planejamento de hidrelétricas em nível de bacias hidrográficas. Conclui-se que foi praticada avaliação de impactos cumulativos no planejamento ambiental da bacia hidrográfica do rio Teles Pires, auferindo-se inclusive algumas das boas práticas internacionais preconizadas pela Avaliação de Impactos Cumulativos.

Considera-se que os impactos cumulativos dos aproveitamentos hidrelétricos inseridos em bacia hidrográfica do rio Teles Pires, na região amazônica, vêm sendo analisados nos instrumentos de planejamento ambiental, principalmente por meio da Avaliação Ambiental Integrada da bacia e, em menor proporção, por meio do Estudo de Impacto Ambiental do aproveitamento hidrelétrico.

Não obstante esses esforços do setor, considerada a associação entre os impactos cumulativos identificados na AAI e os descritos no EIA, o tiering ou encadeamento entre os níveis de planejamento sucessivos - da bacia a hidrelétricas - não se configurou de modo pleno. Bem menos da metade dos impactos cumulativos da AAI apresenta uma associação explícita ao conjunto de impactos ambientais apresentados nos cinco EIAs e apenas para dois EIAs verificou-se que mais da metade dos impactos ambientais está associada aos cumulativos.

Os procedimentos de avaliação de impactos cumulativos em bacias hidrográficas empregados na Avaliação Ambiental Integrada dos aproveitamentos hidrelétricos da bacia do rio Teles Pires estão alinhados ao preconizado pelas boas práticas internacionais. As ressalvas referem-se à não consideração de outras ações do passado e do futuro 
inseridas na bacia hidrográfica, senão as exclusivas das usinas hidrelétricas projetadas. Essa abordagem limita o diagnóstico dos efeitos dos impactos cumulativos sobre os recursos socioambientais afetados e a própria abrangência da proposição de medidas de mitigação e de alternativas nesse contexto.

Há que se ressaltar que o objetivo da AAI é estudar os impactos cumulativos de aproveitamentos hidrelétricos em bacias hidrográficas, o que justifica essa abordagem reducionista quanto às ações consideradas na análise. Entretanto, englobar outras ações que não apenas a construção de hidrelétricas poderia contribuir para a abordagem de outros impactos cumulativos sobre os próprios recursos hídricos, dos quais os aproveitamentos hidrelétricos dependem totalmente e podem estar submetidos ao longo do tempo e comprometer a operação projetada das hidrelétricas.

Quanto aos impactos cumulativos em nível de empreendimento, embora a AAI tenha outros objetivos, garantir a análise da cumulatividade dos impactos em nível de empreendimento está entre os principais e deve ser atingida. $\mathrm{O}$ fato de alguns impactos cumulativos previstos em nível de bacia hidrográfica não terem sido abordados em nível de empreendimento pode ter como um dos principais fatores a falta de hierarquização verificada entre os vários níveis de planejamento no país. Desse modo, perde-se uma importante oportunidade para que os impactos cumulativos avaliados em bacia hidrográfica, cujos procedimentos demonstraram estar alinhados às boas práticas internacionais, pudessem ser adequadamente considerados em projeto, nível em que no Brasil ocorrem as decisões com participação pública.

Os instrumentos de Avaliação Ambiental Integrada e de Estudo de Impacto Ambiental, no contexto de bacia hidrográfica e hidrelétricas, podem ter seu escopo técnico ampliado, no tocante aos impactos cumulativos, de modo a contribuir para o processo de tomada de decisão de oferta de energia hidrelétrica no país.

Recomenda-se que estudos futuros desenvolvam metodologias, dentro do escopo da AAI, que permitam incluir as ações do passado, presente e futuro não diretamente relacionadas a hidrelétricas, dentro do contexto desse estudo técnico, de modo inclusive a otimizar os resultados ambientais de aproveitamentos hidrelétricos em bacias hidrográficas. Recomenda-se, ainda, que a discussão dos impactos cumulativos em nível de empreendimento hidrelétrico possa ser melhorada desde a integração desses estudos em diferentes níveis do planejamento, bem como quanto ao aperfeiçoamento de metodologias existentes que possibilitem ampliar a discussão dessa tipologia de impactos em nível de projetos individuais e que contemplem mecanismos para mitigar esses impactos em nível de projeto. Essas melhorias poderiam contribuir para garantir que todo o esforço realizado para levantar os impactos cumulativos em nível de bacia hidrográfica não seja dissipado em nível de hidrelétricas, onde de fato ocorre a tomada de decisão.

Essas recomendações podem ser inseridas na própria bacia do rio Teles Pires, objeto de estudo dessa pesquisa, quando do desenvolvimento do Estudo de Impacto Ambiental da UHE Magessi, a sexta incluída nessa bacia, para a qual os estudos ambientais ainda não foram realizados e nem a integralização da análise ambiental das PCHs na bacia.

Por fim, é importante enfatizar que a integração da abordagem dos impactos cumulativos nas diferentes escalas do planejamento de bacias hidrográficas por meio de estudos ambientais é uma importante ferramenta para compreender e reduzir os impactos de hidrelétricas em regiões de importantes biomas, como a bacia do rio Teles Pires, na região Amazônica. 


\section{Agradecimentos}

Os autores agradecem à Fundação de Amparo à Pesquisa do Estado de São Paulo (Fapesp) pelo apoio concedido ao financiamento da pesquisa que deu origem a esse artigo científico, por meio do Processo Fapesp nº 2015/20228-1.

\section{Referências}

Almeida, M. R. R.; Malfara, D. T.; Mendes, N. C.; Moraes, M. C. P.; Souza, M. P.; Montano, M. Methods for quality review of environmental impact studies/Aplicação de métodos para revisão da qualidade de estudos de impacto ambiental. Revista de Gestão Ambiental e da Sustentabilidade, 1(2), 3-32, 2012. doi: $10.5585 /$ geas. v1i2.20

ANEEL - Agência Nacional de Energia Elétrica. BIG Banco de Informações de Geração, 2017. Disponível em: $<$ http://www2.aneel.gov.br/aplicacoes/capacidadebrasil/ OperacaoCapacidadeBrasil.cfm>. Acesso em: mar. 2017.

Atkinson, S. F.; Canter, L. W. Assessing the cumulative effects of projects using geographic information systems. Environmental Impact Assessment Review, 31(5), 457-464, 2011. doi: 10.1016/j.eiar.2011.01.008

Bermann, C. Impasses and controversies of hydroelectricity. Estudos Avançados, 21(59), 139-153, 2007. doi: 10.1590/ S0103-40142007000100011

Borioni, R.; Gallardo, A. L. C. F.; Sánchez, L. E. Advancing scoping practice in environmental impact assessment: an examination of the Brazilian federal system. Impact Assessment and Project Appraisal, 35, 200-213, 2017. doi: 10.1080/14615517.2016.1271535

Bidstrup, M., Kørnøv, L.; Partidário, M. R. Cumulative effects in strategic environmental assessment: The influence of plan boundaries. Environmental Impact Assessment Review, 57, 151-158, 2016. doi: 10.1016/j.eiar.2015.12.003

Canter, L. W.; Kamath, J. Questionnaire checklist for cumulative impacts. Environmental Impact Assessment Review, 15(4), 311-339, 1995. doi: 10.1016/0195-9255(95)00010-C

Canter, L.; Chawla, M; Sport, T. Expanding environmental emphases in water resources planning. Journal of Environmental Assessment Policy and Management, 15(4), 1350023, 2013. doi: 10.1142/S1464333213500233
Cardinale, P.; Greig, L. Good practice handbook: cumulative impact assessment and management: guidance for the private sector in emerging markets. Washington, DC: International Corporation, 2013.

Cooper, L. M. Guidelines for Cumulative Effects Assessment in SEA of Plans [EPMG Occasional Paper 04/LMC/CEA]. London, UK: Imperial College London, 2004.

Cooper, L. M.; Sheate, W. R. Integrating cumulative effects assessment into UK strategic planning: implications of the European Union SEA Directive. Impact Assessment and Project Appraisal, 22(1), 5-16, 2004. doi: 10.3152/147154604781766067

Dibo, A. P. A. A inserção de impactos ambientais cumulativos em Estudos de Impacto Ambiental: o caso do setor sucroenergético paulista. São Carlos, Dissertação (Mestrado em Ciências Ambientais) - USP, 2013.

Dibo, A. P. A.; Duarte, C. G.; Agra Filho, S. S.; Malheiros, T. F.; Gallardo, A. L. C. F. Análise preliminar da inserção de impactos cumulativos nos Estudos de Impacto Ambiental do setor sucroenergético no estado de São Paulo. In: Anais da Conferência da Rede de Língua Portuguesa de Avaliação de Impacto, São Paulo, SP, Brasil, 2., 2012. p. 1-13.

EPE - Empresa de Pesquisa Energética. Avaliação ambiental integrada-AAI e diretrizes - Relatório parcial 3 - Sumário executivo. Fase III Levantamentos, Estudos Básicos e de Alternativas, 2009. Disponível em: $<$ http://www.epe.gov. br/MeioAmbiente/Documents/AAI\%20Teles\%20Pires/ AAI\%20Teles\%20Pires\%20-\%20Avaliação\%20Ambiental\%20Integrada\%20e\%20Diretrizes\%20-\%20Sumário\%20 Executivo.pdf $>$. Acesso em: out. 2017.

EPE - Empresa de Pesquisa Energética. UHE Teles Pires - Rima - Relatório de impacto ambiental - RIMA, 2010a. Disponível em: http://www.epe.gov.br/MeioAmbiente/ 
Documents/Rimas/Rima\%20-\%20UHE\%20Teles\%20Pires. pdf. Acesso em: out. 2017.

EPE - Empresa de Pesquisa Energética. UHE Foz do Apiacás - Rima - Relatório de Impacto Ambiental, $2010 \mathrm{~b}$. Disponível em: <http://www.epe.gov.br/MeioAmbiente/ Documents/Rimas/Rima\%20-\%20UHE\%20Foz\%20do\%20 Apiacás.pdf $>$. Acesso em: out. 2017.

EPE - Empresa de Pesquisa Energética. Usina Hidreletrica São Manoel - Relatório de Impacto Ambiental Rima, 2011. Disponível em: $<$ http://www.epe.gov.br/MeioAmbiente/Documents/Rimas/Rima\%20-\%20UHE\%20São\%20Manoel. pdf>. Acesso em: out. 2017.

EPE - Empresa de Pesquisa Energética. Balanço Energético Nacional, 2016. Disponível em: <https://ben.epe.gov.br/>. Acesso em: abr. 2016.

Fearnside, P. M. Amazon dams and waterways: Brazil's Tapajós Basin plans. Ambio, 44(5), 426-439, 2015. doi: 10.1007/s13280-015-0642-z

Fearnside, P. M. Environmental and social impacts of hydroelectric dams in Brazilian Amazonia: Implications for the aluminum industry. World Development, 77, 48-65, 2016. doi: 10.1016/j.worlddev.2015.08.015

Fonseca, A.; Sánchez, L. E.; Ribeiro, J. C. J. Reforming EIA systems: A critical review of proposals in Brazil. Environmental Impact Assessment Review, 62, 90-97, 2017. doi: 10.1016/j.eiar.2016.10.002

Gallardo, A. L. C. F.; Sánchez, L. E. Follow-up of a road building scheme in a fragile environment. Environmental Impact Assessment Review, 24, 47-58, 2004. doi: 10.1016/ S0195-9255(03)00136-7

Gallardo, A. L. C. F.; Bond, A. Capturing the implications of land use change in Brazil through environmental assessment: Time for a strategic approach? Environmental Impact Assessment Review, 31(3), 261-270, 2011. doi: 10.1016/j. eiar.2010.06.002

Gallardo, A. L. C. F.; Duarte, C. G.; Dibo, A. P. A. Avaliação Ambiental Estratégica para o planejamento da expansão da cana-de-açúcar: uma proposta de roteiro. Ambiente \& Sociedade, 19, 67-94, 2016. doi: 10.1590/1809-4422ASO C127007V1922016

Gunn, J.; Noble, B. F. Conceptual and methodological challenges to integrating SEA and cumulative effects as- sessment. Environmental Impact Assessment Review, 31(2), 154-160, 2011. doi: 10.1016/j.eiar.2009.12.003

JGP Consultoria e Participações Ltda. Aproveitamento hidrelétrico Colíder - 300MW. Relatório de Impacto Ambiental - Rima. COPEL, 2009. Disponível em: <http:// www.copel.com/uhecolider/sitearquivos2.nsf/arquivos/ rima/\$FILE/RIMA.pdf>. Acesso em: out. 2017.

Joseph, C.; Zeeg, T.; Angus, D.; Usborne, A.; Mutrie, E. Use of significance thresholds to integrate cumulative effects into Project-level sócio-economic impact assessment in Canada. Environmental Impact Assessment Review, 67, 1-9, 2017. doi: 10.1016/j.eiar.2017.07.003

Junk, W. J.; Mello, J. A. S. Impactos ecológicos das represas hidrelétricas na bacia amazônica brasileira. Estudos Avançados, 4(8), 126-143, 1990. doi: 10.1590/S010340141990000100010

Landim, S. N.; Sánchez, L. E. The contents and scope of environmental impact statements: how do they evolve over time? Impact Assessment and Project Appraisal, 30(4), 217 228, 2012. doi: 10.1080/14615517.2012.746828

MME - Ministério de Minas e Energia. Manual de inventário hidroelétrico de bacias hidrográficas. 2007. Disponível em: <http://www.mme.gov.br/web/guest/publicacoes-e-indicadores/manual-de-inventario-hidroeletrico-de-bacias-hidrograficas>. Acesso em: out. 2017.

Moretto, E. M.; Gomes, C. S.; Roquetti, D. R.; Jordão, C. D. O. Histórico, tendências e perspectivas no planejamento espacial de usinas hidrelétricas brasileiras: a antiga e atual fronteira Amazônica. Ambiente \& Sociedade, 15(3), 141164, 2012. doi: 10.1590/S1414-753X2012000300009

Morgan, R. K. Environmental impact assessment: the state of the art. Impact Assessment and Project Appraisal, 30(1), 5-14, 2012. doi: 10.1080/14615517.2012.661557

Noble, B. F.; Sheelanere, P.; Patrick, R. Advancing watershed cumulative effects assessment and management: lessons from the South Saskatchewan River watershed, Canada. Journal of Environmental Assessment Policy and Management, 13(4), 567-590, 2011. doi: 10.1142/ S1464333211004012

Olagunju, A.; Gunn, J. What influences valued ecosystem component selection for cumulative effects in impact assessment? Journal of Environmental Assessment Policy 
and Management, 15(4), 1350022, 2013. doi: 10.1142/ S1464333213500221

Porto, M.; Tucci, C. E. Planos de recursos hídricos e as avaliações ambientais. Revista de Gestão de Água da América Latina, REGA, 6(2), 19-32, 2009.

Sánchez, L. E. Development of environmental impact assessment in Brazil. UVP Report, 27, 193-200, 2013.

Sánchez, L. E.; Silva-Sánchez, S. S. Tiering Strategic Environmental Assessment and project environmental impact assessment in highway planning in São Paulo, Brazil. Environmental Impact Assessment Review, 28, 512-522, 2008. doi: 10.1016/j.eiar.2008.02.001

Seitz, N. E.; Westbrook, C. J.; Noble, B. F. Bringing science into river systems cumulative effects assessment practice. Environmental Impact Assessment Review, 31(3), 172-179, 2011. doi: 10.1016/j.eiar.2010.08.001

Spaling, H. Cumulative effects assessment: concepts and principles. Impact Assessment, 12(3), 231-251, 1994. doi: 10.1080/07349165.1994.9725865
Themag. Usina hidrelétrica SINOP. Relatório de impacto ambiental - Rima, 2010. Disponível em: <http://www.epe. gov.br/MeioAmbiente/Documents/Rimas/Rima\%20-\%20 UHE\%20Sinop.pdf>. Acesso em: jun. 2016.

Tucci, C. E.; Mendes, C. A. Curso de avaliação ambiental integrada de bacia hidrográfica, 2006. Disponível em: $<$ http://www.mma.gov.br/estruturas/sqa_pnla/_arquivos/ sqa_3.pdf> Acesso em: out. 2017.

Turco, L.E.; Gallardo, A. L. C. F. Avaliação de impacto ambiental e avaliação ambiental estratégica: há evidências de tiering no planejamento de transportes paulista? Gestão \& Regionalidade, no prelo, 2018.

Wärnbäck, A.; Hilding-Rydevik, T. Cumulative effects in Swedish EIA practice - difficulties and obstacles. Environmental Impact Assessment Review, 29(2), 107-115, 2009. doi: 10.1016/j.eiar.2008.05.001

Westin, F. F.; Santos, M. A.; Martins, I. D. Hydropower expansion and analysis of the use of strategic and integrated environmental assessment tools in Brazil. Renewable and Sustainable Energy Reviews, 37, 750-761, 2014. doi: 10.1016/j.rser.2014.04.071 